\title{
角优系列籼粳杂交稻产量及氮素吸收利用的差异
}

$\begin{array}{lllllll}\text { 周 磊 } & \text { 刘秋员 } & \text { 田晋钰 } & \text { 朱梦华 程 爽 车 阳 王志杰 } \\ \text { 邢志鹏 } & \text { 胡雅杰 } & \text { 刘国栋 } & \text { 魏海燕* } & \text { 张洪程 } & & \end{array}$

扬州大学江苏省作物遗传生理重点实验室 / 农业部长江流域稻作技术创新中心 / 粮食作物现代产业技术协同创新中心, 江苏扬州 225009

摘 要: 从 24 个角优系列籼粳杂交稻品种(系)中, 根据不同产量水平和氮素农学利用率篮选出具有代表性的 3 种类 型(高产氮高效、高产氮中效、中产氮中效), 系统比较各类型产量和氮素农学利用率, 以探究高产氮高效型籼粳杂交 稻产量和氮素吸收利用特征。结果表明, 高产氮高效型产量显著高于高产氮中效型和中产氮中效型, 分别高 $4.04 \% \sim 4.38 \%$ 和 $13.37 \% \sim 13.41 \%$, 其高产原因在于群体颖花量大, 能达到 $5.87 \times 10^{8} \sim 6.20 \times 10^{8} \mathrm{hm}^{-2}$ 。与高产氮中效型和 中产氮中效型相比, 高产氮高效型成穗率高, 能保持在 $68.83 \% \sim 70.05 \%$; 抽穗期叶面积指数高, 且生育后期衰减平缓, 成熟期叶面积指数在 3.85 以上; 抽穗至成熟期干物质积累量大, 达 7.91 7.99 t hm${ }^{-2}$, 全生育期干物质量可达 $21.15 \sim 21.46 \mathrm{t} \mathrm{hm}^{-2}$ 。在氮素吸收利用方面, 高产氮高效型总吸氮量显著高于高产氮中效型和中产氮中效型, 分别高 5.07\% $5.14 \%$ 和 $4.50 \%$ 5.96\%; 拔节至抽穗期和抽穗至成熟期氮素吸收速率表现为高产氮高效型>高产氮中效型>中 产氮中效型, 花后茎鞘氮素转运量、穗部氮素积累量和氮素收获指数也有相同表现; 氮素回收利用率、农学利用率、 生理利用率和偏生产力均以高产氮高效型最高; 高产氮中效型除氮素回收利用率和百千克籽粒吸氮量外, 其他各项 氮素利用指标均高于中产氮中效型。

关键词: 角优系列籼粳杂交稻; 高产氮高效; 产量; 氮素

\section{Differences in yield and nitrogen absorption and utilization of indica-japonica hybrid rice varieties of Yongyou series}

ZHOU Lei, LIU Qiu-Yuan, TIAN Jin-Yu, ZHU Meng-Hua, CHENG Shuang, CHE Yang, WANG Zhi-Jie, XING Zhi-Peng, HU Ya-Jie, LIU Guo-Dong, WEI Hai-Yan*, and ZHANG Hong-Cheng*

Jiangsu Key Laboratory of Crop Genetics and Physiology / Innovation Center of Rice Cultivation Technology in Yangtze Valley, Ministry of Agriculture / Co-Innovation Center for Modern Production Technology of Grain Crops, Yangzhou University, Yangzhou 225009, Jiangsu, China

\begin{abstract}
A field experiment was conducted with 24 indica-japonica hybrid rice varieties (lines) of Yongyou series, from which three types (high yield and high AE (agronomic nitrogen use efficiency) [HH], high yield and medium AE [HM], medium yield and medium $\mathrm{AE}[\mathrm{MM}]$ ) were selected to explore the characteristics of varieties with high yield and high AE. The yield of HH type was $4.04 \%-4.38 \%$ and $13.37 \%-13.41 \%$ higher than that of HM type and MM type respectively, owing to the larger number of total spikelets, which was $5.87 \times 10^{8}-6.20 \times 10^{8} \mathrm{hm}^{-2}$. Compared with HM and MM type, HH type had a high percentage of tiller rate, which was $68.83 \%-70.05 \%$. The LAI of $\mathrm{HH}$ type was maximum at heading stage and declined slowly after heading. As a result, the LAI of HH type was above 3.85 at maturity stage. The dry matter accumulation of HH type was 7.91-7.99 $\mathrm{t}$
\end{abstract}

本研究由国家重点研发计划项目 (2016YFD0300503)，国家自然科学基金项目(31971841)，国家现代农业产业技术体系建设专项 (CARS-01-27)，江苏省重点研发计划项目(BE2016344，BE2018355)，江苏省农业产业技术体系专项(JATS[2018]298)和扬州大学拔尖人 才计划资助。

This study was supported by the National Key Research and Development Program of China (2016YFD0300503), the National Natural Science Foundation of China (31971841), the China Agriculture Research System (CARS-01-27), the Key Research Program of Jiangsu Province (BE2016344, BE2018355), the earmarked fund for Jiangsu Agricultural Industry Technology System (JATS[2018]298), and the Program for Scientific Elitists of Yangzhou University.

*通信作者(Corresponding authors): 张洪程,E-mail: hczhang@yzu.edu.cn; 魏海燕, E-mail: wei_haiyan@163.com 
$\mathrm{hm}^{-2}$ from heading to maturity, which was the highest in three types, and its dry matter accumulation was more than $21.15-21.46 \mathrm{t} \mathrm{hm}^{-2}$ in the whole growth period. The total nitrogen uptake of HH type showed $5.07 \%-5.14 \%$ and $4.50 \%-5.96 \%$ increase than that of HM type and MM type respectively at maturity stage. The nitrogen sbsorption rate from jointing to heading stage and from heading to maturity stage showed HH type $>$ HM type $>$ MM type, as well as NTSH (N transportation from stem after heading), NIPH ( $\mathrm{N}$ increase in panicle after heading) and NHI ( $\mathrm{N}$ harvest index). HH type had the highest NRE (nitrogen recovery use efficiency), AE, PE (physiological nitrogen use efficiency) and PFP (partial factor productivity of applied N). Expect for NRE and NRG (nitrogen requirement for $100 \mathrm{~kg}$ grain), all the other nitrogen utilization indexes of HM type were higher than that of MM type.

Keywords: indica-japonica hybrid rice varieties of Yongyou series; high yield and high agronomic nitrogen use efficiency; yield; nitrogen

随着人口的增长, 人们对水稻的需求量日益增 加; 与此同时，城镇化的不断推进导致了可用农田 的减少 ${ }^{[1]}$, 土地资源日渐稀缺; 因此，提高水稻单产 是增加粮食产量的重要途径 ${ }^{[2]}$ 。水稻籼粳亚种间的 杂种优势对水稻单产提高有重要意义 ${ }^{[3]}$ 。近年来, 浙 江省宁波农业科学院、中国水稻研究所等机构利用 粳型不育系与籼粳中间型广亲和恢复系配组, 培育 出甬优系列 ${ }^{[4]} 、$ 春优系列 ${ }^{[5]} 、$ 浙优系列 ${ }^{[6]}$ 等新组合, 其 中甬优系列籼粳杂交稻表现最佳, 在生产试验和大 面积推广中均获得较好的产量表现 ${ }^{[7-9]}$ 。前人研究发 现, 相较于其他类型水稻, 角优系列籼粳杂交稻穗 大粒多, 库容量大 ${ }^{[10]}$; 根系生物量大、分支结构优, 根冠协调水平高, 生育中后期根系活力强 ${ }^{[11]}$; 上三 叶长而内卷挺立, 群体上下受光姿态好 ${ }^{[12]}$, 冠层结 构和光合特性优势明显 ${ }^{[13]}$; 生育中后期光合生产能 力强、干物质积累量大, 收获指数高 ${ }^{[14]}$; 单茎茎鞘干 重和单位长度节间干重大, 茎秆充实度高 ${ }^{[15]}$, 抗倒 能力较强 ${ }^{[16]}$ 。

氮素是水稻生长发育必不可少的元素, 施用氮 肥可以有效提高水稻产量 ${ }^{[17]}$ 。我国每年氮肥施用量 占全球 $37 \%^{[18]}$, 农民习惯于通过施用过量的肥料 来获得高产, 过量施肥不仅降低了氮肥利用率, 而 且还会引发环境问题 ${ }^{[19}$ 。因此, 在提高产量的同时, 协同提高氮肥利用率是水稻科研工作者的主要任 务 ${ }^{[20]}$ 。李超等 ${ }^{[21]}$ 研究发现, 角优系列籼粳杂交稻抽 穗期和成熟期植株含氮率和氮积累量极显著大于对 照(常规粳稻和杂交籼稻), 氮素偏生产力极显著大 于常规粳稻, 氮素䊏粒生产效率、氮素干物质生产 效率和氮素收获指数显著低于杂交籼稻; 陈贵等 ${ }^{[22]}$ 有相似发现, 相较于常规粳稻, 籼粳杂交稻氮素吸 收能力强, 总吸氮量高; 韦还和等 ${ }^{[2]]}$ 研究发现, 籼 粳杂交稻花后氮素积累能力强是因为快增期天数显 著多于对照(常规粳稻和杂交籼稻)。综上, 籼粳杂交 稻吸氮量高于其他类型水稻, 但是氮素利用方面优
势不明显, 因此篩选氮素利用能力强的籼粳杂交稻 品种至关重要。

籼粳杂交稻不同品种获得高产的途径不尽相同, 有在穗粒数和千粒重相当条件下, 以单位面积穗数 多和结实率高获得高产的 ${ }^{[15]}$; 有在群体颖花量相当 条件下, 以高千粒重和高结实率获得高产的 ${ }^{[24]}$; 也 有在千粒重和结实率相当条件下, 以较大群体颖花 量获得高产的 ${ }^{[25]}$ 。氮素利用方面, 也是各有差异: 汪 峰等 ${ }^{[26]}$ 研究甬优系列籼粳杂交稻不同株高品种氮素 利用率的差异时发现, 高秆型品种氮肥吸收利用率 显著高于矮秆型和中高秆型品种, 但氮肥偏生产力 和氮素收获指数没有优势。韦还和等 ${ }^{[27]}$ 研究发现, 与一般高产群体相比, 甬优 12 超高产群体氮素吸收 具有拔节期低, 抽穗期和成熟期高的特点, 但氮素 杼粒生产率偏低。

上述研究大多集中在籼粳杂交稻与其他类型水 稻产量、氮素吸收、物质积累特性的比较上, 而对 于同种类型不同品种籼粳杂交稻的比较研究相对较 少。为此, 本试验收集了24个角优系列籼粳杂交稻 品种(系), 根据其产量和氮素农学利用率的差异, 篮 选出高产氮高效、高产氮中效和中产氮中效 3 种类型, 并从每种类型簃选出具有代表性的 2 个品种, 系统 比较3种类型甬优系列籼粳杂交稻产量及其构成因 素、干物质生产和氮素吸收利用方面的差异, 深入 分析差异形成原因, 阐明其品种特征, 以期为甬优 系列籼粳杂交稻的高产氮高效栽培与育种提供理论 依据。

\section{1 材料与方法}

\section{1 试验地点与供试材料}

试验于 2017-2018 年在扬州大学农学院校外试 验点，泰州市姜堰区沈高镇即江苏省稻麦科技综合 示范基地进行, 土壤类型为㵔育型水稻土, 质地黏 性。0 20 cm 土层含有机质质量分数 $31.72 \mathrm{~g} \mathrm{~kg}^{-1}$ 、 
全氮 $1.96 \mathrm{~g} \mathrm{~kg}^{-1}$ 、速效钾 $165.26 \mathrm{mg} \mathrm{kg}$ 、速效磷 $62.54 \mathrm{mg} \mathrm{kg}^{-1}$, 前茬为小麦。

2017 年选用 24 个角优系列籼粳杂交稻品种(系) 进行, 供试品种均为杂交品种, 2018 年根据前一年 各品种(系)病虫害抗性、倒伏情况以及生育期情况, 筛选出 16 个适宜当地种植的品种(系)进行试验。根 据产量和氮素农学利用率(表 1)筛选出生产上最具
代表性的高产氮高效型(产量 $>10.5 \mathrm{t} \mathrm{hm}^{-2}$ 且氮素农 学利用率 $>18.5 \mathrm{~kg} \mathrm{~kg}^{-1}$ ) 品种角优 1662 和角优 4949 , 高产氮中效型(产量 $>10.5 \mathrm{t} \mathrm{hm}^{-2}$ 且氮素农学利用率> $14.5 \mathrm{~kg} \mathrm{~kg}^{-1}$ )品种甬优 2640 和角优 4953, 中产氮中 效型(产量 $<10 \mathrm{t} \mathrm{hm}^{-2}$ 且氮素农学利用率 $>14.5 \mathrm{~kg} \mathrm{~kg}^{-1}$ ) 品种角优 6715 和甬优 6760 , 共 6 个, 研究其产量和 氮素吸收利用的差异。

表 1 角优系列籼粳杂交稻产量及氮素农学利用率的差异

Table 1 Differences in yield and agronomic nitrogen use efficiency (AE) of indica-japonica hybrid rice varieties of Yongyou series

\begin{tabular}{|c|c|c|c|c|}
\hline \multirow{2}{*}{$\begin{array}{c}\text { 品种名称/年份 } \\
\text { Variety/year }\end{array}$} & \multicolumn{2}{|c|}{2017} & \multicolumn{2}{|c|}{2018} \\
\hline & $\begin{array}{c}\text { 产量 } \\
\text { Yield }\left(\mathrm{t} \mathrm{hm}^{-2}\right)\end{array}$ & $\begin{array}{c}\text { 氮素农学利用率 } \\
\mathrm{AE}\left(\mathrm{kg} \mathrm{kg}^{-1}\right)\end{array}$ & $\begin{array}{c}\text { 产量 } \\
\text { Yield }\left(\mathrm{t} \mathrm{hm}^{-2}\right)\end{array}$ & $\begin{array}{c}\text { 氮素农学利用率 } \\
\mathrm{AE}\left(\mathrm{kg} \mathrm{kg}^{-1}\right)\end{array}$ \\
\hline 角优 1206 Yongyou 1206 & 8.80 & 10.84 & 8.96 & 12.68 \\
\hline 角优 1218 Yongyou 1218 & 9.16 & 11.56 & 9.19 & 10.47 \\
\hline 角优 1271 Yongyou 1271 & 8.62 & 11.15 & 8.77 & 12.23 \\
\hline 角优 1526 Yongyou 1526 & 9.59 & 12.56 & 9.71 & 13.46 \\
\hline 角优 1662 Yongyou 1662 & 11.13 & 18.81 & 11.21 & 19.18 \\
\hline 角优 1826 Yongyou 1826 & 9.60 & 13.43 & 9.56 & 12.36 \\
\hline 角优 2519 Yongyou 2519 & 9.54 & 10.44 & 9.45 & 12.12 \\
\hline 角优 2640 Yongyou 2640 & 10.69 & 15.88 & 10.77 & 16.94 \\
\hline 角优 4949 Yongyou 4949 & 11.03 & 18.60 & 11.18 & 19.14 \\
\hline 角优 4953 Yongyou 4953 & 10.62 & 15.99 & 10.67 & 16.52 \\
\hline 角优 6715 Yongyou 6715 & 9.77 & 14.79 & 9.89 & 15.94 \\
\hline 角优 6760 Yongyou 6760 & 9.76 & 15.09 & 9.85 & 15.43 \\
\hline 角优 6763 Yongyou 6763 & 10.24 & 16.95 & 10.09 & 15.37 \\
\hline 角优 7053 Yongyou 7053 & 8.80 & 11.38 & 8.85 & 12.01 \\
\hline 角优 7722 Yongyou 7722 & 9.05 & 12.22 & 9.11 & 11.52 \\
\hline 角优 8484 Yongyou 8484 & 8.88 & 9.32 & 9.03 & 9.43 \\
\hline 平均 Mean & 9.71 & 13.69 & 9.77 & 14.05 \\
\hline 标准差 SD & 0.80 & 2.87 & 0.79 & 2.86 \\
\hline 变异系数 CV (\%) & 8.22 & 20.98 & 8.07 & 20.34 \\
\hline
\end{tabular}

CV: coefficient of variation; SD: standard deviation.

\section{2 试验设计}

两年试验均于 6 月 13 日播种, 6 月 24 日移栽, 行株 距为 $25 \mathrm{~cm} \times 6 \mathrm{~cm}$, 单本栽插。采用随机区组设计, 氮 肥施用量为 $270 \mathrm{~kg} \mathrm{hm}^{-2}$, 以不施氮肥为空白对照, 小区 面积 $15 \mathrm{~m}^{2}$, 重复 3 次。氮肥按基藮肥: 穗肥 $=7: 3$ 施 用。基肥: 第 1 次分菜肥: 第 2 次分菜肥: 穗肥 $=3$ : 2: $2: 3$ 。分竪肥于移栽后 $7 \mathrm{~d}$ 和四叶一心时分两次等 量施用, 穗肥于倒四叶期施用。氮 $($ 纯 $\mathrm{N})$ ：磷 $\left(\mathrm{P}_{2} \mathrm{O}_{5}\right)$ ：钾 $\left(\mathrm{K}_{2} \mathrm{O}\right)$ 比例为 $2: 1: 2$, 磷肥一次性基施, 钾肥分别于耕 翻前、拔节期等量施入。水分管理及病虫草害防治等相 关的栽培措施均按照高产栽培要求实施。

\section{3 测定项目与方法}

1.3.1 茎雀动态 每个小区连续选定 10 穴作为 一个观察点, 移栽后 $20 \mathrm{~d}$ 开始观察茎䔣动态, 每隔 7 $\mathrm{d}$ 一次, 直至抽穗期为止。

1.3.2 叶面积于拔节期、抽穗期、成熟期, 按 每小区茎藍数的平均数取代表性植株 3 穴, 采用长 宽法测定叶面积。

1.3.3 千物质 于拔节期、抽穗期、成熟期, 按 每小区茎藍数的平均值取代表性植株 3 穴, 分器官 $105^{\circ} \mathrm{C}$ 下杀青 $30 \mathrm{~min}, 80^{\circ} \mathrm{C}$ 下烘干至恒重, 测定各器 官干物质重。 
1.3.4 产量测定成熟期，普查每小区 100 穴， 计算有效穗数, 按平均穗数取 5 穴调查每穗粒数、 结实率与测定千粒重, 计算理论产量, 成熟后实收 每小区测产。

1.3.5 氮素测定将拔节期、抽穗期、成熟期各 器官(茎鞘、叶片、穗)烘干后粉碎, 采用 $\mathrm{H}_{2} \mathrm{SO}_{4}-\mathrm{H}_{2} \mathrm{O}_{2}$ 消化, 以半微量凯氏定氮法测定各器官以及各时期 植株含氮率。

1.3.6 数据计算 叶面积指数衰减率 $\left(\right.$ LAI d $\left.{ }^{-1}\right)=$ (抽穗期叶面积指数 - 成熟期叶面积指数)/抽穗至成 熟期间隔天数; 光合势 $\left(\mathrm{m}^{2} \mathrm{~d} \mathrm{~m}^{-2}\right)=\left(\mathrm{LAI}_{1}+\right.$ $\left.\mathrm{LAI}_{2}\right) \times\left(\mathrm{t}_{2}-\mathrm{t}_{1}\right) / 2$; 式中, $\mathrm{LAI}_{1}$ 和 $\mathrm{LAI}_{2}$ 为前后 2 次测定 的叶面积指数, $t_{1}$ 和 $t_{2}$ 为前后 2 次测定间隔的时间; 群体生长率 $\left(\mathrm{g} \mathrm{m}^{2} \mathrm{~d}^{-1}\right)=\left(\mathrm{W}_{2}-\mathrm{W}_{1}\right) /\left(\mathrm{t}_{2}-\mathrm{t}_{1}\right), \mathrm{W}_{1} 、 \mathrm{~W}_{2}$ 代表前后两次测定的干物质重, $\mathrm{t}_{1}$ 和 $\mathrm{t}_{2}$ 为前后 2 次测 定间隔的时间; 净同化率 $\left(\mathrm{g} \mathrm{m}^{2} \mathrm{~d}^{-1}\right)=\left[\left(\mathrm{ln} \mathrm{LAI}_{2}-\ln \right.\right.$ $\left.\left.\mathrm{LAI}_{1}\right) /\left(\mathrm{LAI}_{2}-\mathrm{LAI}_{1}\right)\right] \times\left[\left(\mathrm{W}_{2}-\mathrm{W}_{1}\right) /\left(\mathrm{t}_{2}-\mathrm{t}_{1}\right)\right], \mathrm{LAI}_{1}$ 和 $\mathrm{LAI}_{2}$ 为前后 2 次测定的叶面积指数, $\mathrm{W}_{1} 、 \mathrm{~W}_{2}$ 为前后 2 次测定的干物质重, $t_{1}$ 和 $t_{2}$ 为前后 2 次测定间隔的 时间; 成穗率 $=$ 有效穗数/高峰苗数 $\times 100 \%$; 氮素 吸收量 $\left(\mathrm{kg} \mathrm{hm}^{-2}\right)=$ 该时期地上部干物重 $\times$ 含氮率; 氮素阶段吸收量 $\left(\mathrm{kg} \mathrm{hm}^{-2}\right)=$ 后一时期氮素吸收量一 前一时期氮素吸收量; 氮素阶段积累比例 $=$ 氮素 阶段积累量/成熟期氮素积累量 $\times 100 \%$; 氮素阶段吸 收速率 $\left(\mathrm{kg} \mathrm{hm}^{-2} \mathrm{~d}^{-1}\right)=$ 氮素阶段吸收量/前后两时期 间隔天数; 抽穗后叶片(茎鞘)氮素转运量 $\left(\mathrm{kg} \mathrm{hm}^{-2}\right)=$ 抽穗期叶片(茎鞘)氮素积累量一成熟期叶片(茎鞘)氮 素积累量; 抽穗后穗部氮素积累量 $\left(\mathrm{kg} \mathrm{hm}^{-2}\right)=$ 成熟 期穗部氮素积累量-抽穗期穗部氮素积累量; 氮素回
收利用率 $(\%)=($ 施氮区水稻吸氮量一氮空白区水稻吸 氮量) /施氮量 $\times 100$; 氮素农学利用率 $\left(\mathrm{kg} \mathrm{kg}^{-1}\right)=$ (施 氮区籽粒产量一氮空白区籽粒产量)/施氮量; 氮素生 理利用率 $\left(\mathrm{kg} \mathrm{kg}^{-1}\right)=($ 施氮区籽粒产量一氮空白区籽粒 产量)/(施氮区水稻吸氮量一氮空白区水稻吸氮量); 氮 肥偏生产力 $\left(\mathrm{kg} \mathrm{kg}^{-1}\right)=$ 水稻产量/施氮量; 百千克籽粒 吸氮量 $(\mathrm{kg})=$ 氮素总积累量/稻谷产量 $\times 100$ 。

1.3.7 数据分析 运用 Microsoft Excel 软件进 行数据录入与计算, 用 SPSS 23.0 软件统计分析。

\section{2 结果与分析}

2.1 不同类型角优系列籼粳杂交稻产量及构成 因素的差异

群体颖花量和产量均表现为高产氮高效型>高 产氮中效型>中产氮中效型(表 2), 差异显著, 与中 产氮中效型相比，高产氮高效型和高产氮中效型群 体颖花量和产量分别高 $24.63 \%$ 30.80\%、11.68\% $12.24 \%$ 和 $13.37 \% \sim 13.41 \% 、 8.61 \% \sim 9.01 \%$; 3 种类型 水稻在结实率和千粒重上差异显著, 其中以高产氮 中效型结实率最高，中产氮中效型千粒重最高。同 为籼粳杂交稻, 3 种类型在结实率和千粒重上表现不 一, 说明籼粳杂交稻产量差异主要体现在群体颖花 量上。

2.2 不同类型角优系列籼粳杂交稻株高及成穗 率的差异

株高和高峰苗均表现为高产氮高效型<高产氮 中效型 $<$ 中产氮中效型(表 3), 与中产氮中效型相比, 高产氮高效型、高产氮中效型株高和高峰苗分别低 $9.08 \% \sim 10.16 \%$ 、 $5.44 \% \sim 6.36 \%$ 和 $2.79 \% \sim 2.80 \%$ 、

表 2 角优系列籼粳杂交稻产量及构成因素的差异

Table 2 Differences in yield and components of indica-japonica hybrid rice varieties of Yongyou series

\begin{tabular}{|c|c|c|c|c|c|c|c|}
\hline $\begin{array}{c}\text { 品种类型 } \\
\text { Type }\end{array}$ & $\begin{array}{c}\text { 品种名称 } \\
\text { Variety }\end{array}$ & $\begin{array}{c}\text { 单位面积穗数 } \\
\text { No. of panicles } \\
\left(\times 10^{4} \mathrm{hm}^{-2}\right)\end{array}$ & $\begin{array}{l}\text { 每穗粒数 } \\
\text { Spikelets } \\
\text { per panicle }\end{array}$ & $\begin{array}{c}\text { 总颖花量 } \\
\text { Total spikelet } \\
\text { number } \\
\left(\times 10^{8} \mathrm{hm}^{-2}\right) \\
\end{array}$ & $\begin{array}{c}\text { 结实率 } \\
\text { Percentage of } \\
\text { filled grain } \\
(\%)\end{array}$ & $\begin{array}{c}\text { 千粒重 } \\
\text { 1000-grain } \\
\text { weight } \\
(\mathrm{g})\end{array}$ & $\begin{array}{c}\text { 产量 } \\
\text { Yield } \\
\left(\mathrm{t} \mathrm{hm}^{-2}\right)\end{array}$ \\
\hline \multicolumn{8}{|l|}{2017} \\
\hline 高产氮高效 & 甬优 1662 Yongyou 1662 & 241.03 & 243.40 & 5.87 & 81.87 & 24.18 & 11.13 \\
\hline $\mathrm{HH}$ & 角优 4949 Yongyou 4949 & 238.39 & 246.23 & 5.87 & 82.33 & 23.90 & 11.03 \\
\hline 高产氮中效 & 甬优 2640 Yongyou 2640 & 234.00 & 221.41 & 5.18 & 85.70 & 24.20 & 10.69 \\
\hline $\mathrm{HM}$ & 角优 4953 Yongyou 4953 & 237.08 & 224.75 & 5.33 & 86.04 & 23.67 & 10.62 \\
\hline 中产氮中效 & 角优 6715 Yongyou 6715 & 218.27 & 215.33 & 4.70 & 81.35 & 28.65 & 9.77 \\
\hline \multirow[t]{4}{*}{$\mathrm{MM}$} & 角优 6760 Yongyou 6760 & 219.08 & 214.78 & 4.71 & 82.02 & 28.47 & 9.76 \\
\hline & $\mathrm{HH}$ 平均值 $\mathrm{HH}$ mean & $239.71 \mathrm{a}$ & $244.82 \mathrm{a}$ & $5.87 \mathrm{a}$ & $82.10 \mathrm{~b}$ & $24.04 \mathrm{~b}$ & $11.08 \mathrm{a}$ \\
\hline & $\mathrm{HM}$ 平均值 $\mathrm{HM}$ mean & $235.54 \mathrm{a}$ & $223.08 \mathrm{~b}$ & $5.26 \mathrm{~b}$ & $85.87 \mathrm{a}$ & $23.83 \mathrm{~b}$ & $10.65 \mathrm{~b}$ \\
\hline & $\mathrm{MM}$ 平均值 $\mathrm{MM}$ mean & $218.68 \mathrm{~b}$ & $215.05 \mathrm{c}$ & $4.71 \mathrm{c}$ & $81.68 \mathrm{~b}$ & $28.56 \mathrm{a}$ & $9.77 \mathrm{c}$ \\
\hline
\end{tabular}


(续表 2)

\begin{tabular}{|c|c|c|c|c|c|c|c|}
\hline $\begin{array}{c}\text { 品种类型 } \\
\text { Type }\end{array}$ & $\begin{array}{c}\text { 品种名称 } \\
\text { Variety }\end{array}$ & $\begin{array}{c}\text { 单位面积穗数 } \\
\text { No. of panicles } \\
\left(\times 10^{4} \mathrm{hm}^{-2}\right)\end{array}$ & $\begin{array}{l}\text { 每穗粒数 } \\
\text { Spikelets } \\
\text { per panicle }\end{array}$ & $\begin{array}{c}\text { 总颖花量 } \\
\text { Total spikelet } \\
\text { number } \\
\left(\times 10^{8} \mathrm{hm}^{-2}\right)\end{array}$ & $\begin{array}{c}\text { 结实率 } \\
\text { Percentage of } \\
\text { filled grain } \\
(\%)\end{array}$ & $\begin{array}{c}\text { 千粒重 } \\
\text { 1000-grain } \\
\text { weight } \\
(\mathrm{g})\end{array}$ & $\begin{array}{c}\text { 产量 } \\
\text { Yield } \\
\left(\mathrm{t} \mathrm{hm}^{-2}\right)\end{array}$ \\
\hline \multicolumn{8}{|l|}{2018} \\
\hline 高产氮高效 & 角优 1662 Yongyou 1662 & 246.08 & 253.38 & 6.24 & 79.46 & 24.17 & 11.21 \\
\hline $\mathrm{HH}$ & 角优 4949 Yongyou 4949 & 240.37 & 256.14 & 6.16 & 79.56 & 23.96 & 11.18 \\
\hline 高产氮中效 & 角优 2640 Yongyou 2640 & 232.03 & 232.33 & 5.39 & 84.38 & 24.51 & 10.77 \\
\hline $\mathrm{HM}$ & 角优 4953 Yongyou 4953 & 228.30 & 229.73 & 5.24 & 85.68 & 24.07 & 10.67 \\
\hline 中产氮中效 & 角优 6715 Yongyou 6715 & 215.91 & 220.75 & 4.77 & 80.91 & 28.65 & 9.89 \\
\hline \multirow[t]{4}{*}{ MM } & 角优 6760 Yongyou 6760 & 217.81 & 216.80 & 4.72 & 80.67 & 28.47 & 9.85 \\
\hline & $\mathrm{HH}$ 平均值 $\mathrm{HH}$ mean & $243.23 \mathrm{a}$ & $254.76 \mathrm{a}$ & $6.20 \mathrm{a}$ & $79.51 \mathrm{~b}$ & $24.07 \mathrm{~b}$ & $11.19 \mathrm{a}$ \\
\hline & $\mathrm{HM}$ 平均值 $\mathrm{HM}$ mean & $230.16 b$ & $231.03 \mathrm{~b}$ & $5.32 \mathrm{~b}$ & $85.03 \mathrm{a}$ & $24.29 \mathrm{~b}$ & $10.72 \mathrm{~b}$ \\
\hline & $\mathrm{MM}$ 平均值 $\mathrm{MM}$ mean & $216.86 \mathrm{c}$ & $218.77 \mathrm{c}$ & $4.74 \mathrm{c}$ & $80.79 \mathrm{~b}$ & $28.56 \mathrm{a}$ & $9.87 \mathrm{c}$ \\
\hline
\end{tabular}

同一类型同一列数据后不同小写字母表示在 0.05 水平下差异显著。

Within a column for the same variety type, values followed by different small letters are significantly different at the 0.05 probability level. $\mathrm{HH}$ : high yield and high agronomic nitrogen use efficiency; HM: high yield and medium agronomic nitrogen use efficiency; MM: medium yield and medium agronomic nitrogen use efficiency.

\section{表 3 角优系列籼粳杂交稻株高及茎藮动态的差异}

Table 3 Differences in plant height and dynamic of tillers of indica-japonica hybrid rice varieties of Yongyou series

\begin{tabular}{|c|c|c|c|c|c|}
\hline $\begin{array}{c}\text { 品种类型 } \\
\text { Type }\end{array}$ & $\begin{array}{c}\text { 品种名称 } \\
\text { Variety }\end{array}$ & $\begin{array}{c}\text { 株高 } \\
\text { Plant height } \\
(\mathrm{cm})\end{array}$ & $\begin{array}{c}\text { 高峰苗 } \\
\text { Peak seeding } \\
\left(\times 10^{4} \mathrm{hm}^{-2}\right)\end{array}$ & $\begin{array}{c}\text { 单位面积穗数 } \\
\text { No. of panicles } \\
\left(\times 10^{4} \mathrm{hm}^{-2}\right)\end{array}$ & $\begin{array}{c}\text { 成穗率 } \\
\text { RPTT } \\
(\%) \\
\end{array}$ \\
\hline \multicolumn{6}{|l|}{2017} \\
\hline 高产氮高效 & 角优 1662 Yongyou 1662 & 110.4 & 347.06 & 241.03 & 69.45 \\
\hline $\mathrm{HH}$ & 角优 4949 Yongyou 4949 & 111.8 & 349.49 & 238.39 & 68.21 \\
\hline 高产氮中效 & 角优 2640 Yongyou 2640 & 114.5 & 351.42 & 234.00 & 66.59 \\
\hline HM & 角优 4953 Yongyou 4953 & 116.6 & 352.78 & 237.08 & 67.20 \\
\hline 中产氮中效 & 角优 6715 Yongyou 6715 & 122.6 & 357.97 & 218.27 & 60.97 \\
\hline \multirow[t]{4}{*}{ MM } & 角优 6760 Yongyou 6760 & 121.8 & 358.65 & 219.08 & 61.08 \\
\hline & $\mathrm{HH}$ 平均值 $\mathrm{HH}$ mean & $111.10 \mathrm{~b}$ & $348.27 \mathrm{c}$ & $239.71 \mathrm{a}$ & $68.83 \mathrm{a}$ \\
\hline & $\mathrm{HM}$ 平均值 $\mathrm{HM}$ mean & $115.55 \mathrm{~b}$ & $352.10 \mathrm{~b}$ & $235.54 \mathrm{a}$ & $66.89 \mathrm{a}$ \\
\hline & $\mathrm{MM}$ 平均值 $\mathrm{MM}$ mean & $122.20 \mathrm{a}$ & $358.31 \mathrm{a}$ & $218.68 \mathrm{~b}$ & $61.03 \mathrm{~b}$ \\
\hline \multicolumn{6}{|l|}{2018} \\
\hline 高产氮高效 & 角优 1662 Yongyou 1662 & 109.7 & 349.25 & 246.08 & 70.46 \\
\hline HH & 角优 4949 Yongyou 4949 & 110.5 & 345.16 & 240.37 & 69.64 \\
\hline 高产氮中效 & 角优 2640 Yongyou 2640 & 113.8 & 351.12 & 232.03 & 66.08 \\
\hline HM & 角优 4953 Yongyou 4953 & 115.7 & 350.58 & 228.30 & 65.12 \\
\hline 中产氮中效 & 角优 6715 Yongyou 6715 & 122.7 & 360.03 & 215.91 & 59.97 \\
\hline \multirow[t]{4}{*}{ MM } & 角优 6760 Yongyou 6760 & 122.4 & 357.36 & 217.81 & 60.95 \\
\hline & $\mathrm{HH}$ 平均值 $\mathrm{HH}$ mean & $110.10 \mathrm{c}$ & $348.70 \mathrm{~b}$ & $243.23 \mathrm{a}$ & $70.05 \mathrm{a}$ \\
\hline & $\mathrm{HM}$ 平均值 $\mathrm{HM}$ mean & $114.75 \mathrm{~b}$ & $350.85 \mathrm{~b}$ & $230.16 \mathrm{~b}$ & $65.60 \mathrm{~b}$ \\
\hline & $\mathrm{MM}$ 平均值 $\mathrm{MM}$ mean & $122.55 \mathrm{a}$ & $358.70 \mathrm{a}$ & $216.86 \mathrm{c}$ & $60.46 \mathrm{c}$ \\
\hline
\end{tabular}

同一类型同一列数据后不同小写字母表示在 0.05 水平下差异显著。

Within a column for the same variety type, values followed by different small letters are significantly different at the 0.05 probability level. RPTT: ratio of productive tillers to total tillers; HH: high yield and high agronomic nitrogen use efficiency; HM: high yield and medium agronomic nitrogen use efficiency; MM: medium yield and medium agronomic nitrogen use efficiency. 
1.73\% 2.19\%; 高产氮高效型和高产氮中效型成穗 率显著高于中产氮中效型，分别高 $12.78 \%$ 15.86\%、 $8.50 \% \sim 9.60 \%$ 。

\section{3 不同类型角优系列籼粳杂交稻各生育阶段} 物质积累及其比例的差异

移栽一拔节期干物质积累量和比例表现为中产 氮中效型>高产氮高效型、高产氮中效型，抽穗一成 熟期干物质积累量和比例表现则相反(表 4)。与中产 氮中效型相比, 高产氮高效和高产氮中效型移栽一 拔节期干物质积累量分别低 6.61\% 6.64\%、5.03\% $6.03 \%$ ，移栽一拔节期积累比例分别低 $13.33 \%$ $14.11 \% 、 10.34 \% \sim 10.96 \%$; 抽穗一成熟期干物质积累 量分别高 $20.95 \% \sim 24.26 \% 、 15.09 \% \sim 15.60 \%$ ，抽穗-
成熟期积累比例分别高 $12.24 \%$ 14.06\%、9.04\% $9.36 \%$ 。高产氮高效型和高产氮中效型群体总干物重 和收获指数均显著高于中产氮中效型, 群体干物重 分别高 $7.44 \% \sim 8.93 \% 、 5.48 \% \sim 5.71 \%$ ，收获指数分别 高 $5.39 \% \sim 4.11 \%$ 、2.91\% 3.32\%。

2.4 不同类型角优系列籼粳杂交稻叶面积指数 及结实期叶面积衰减率的差异

拔节期叶面积指数表现为中产氮中效型>高产 氮高效型、高产氮中效型，抽穗期和成熟期则相反 (表 5)。与中产氮中效型相比，高产氮高效型和高产 氮中效型拔节期叶面积指数分别低 $2.88 \%$ 3.98\%、 $2.88 \% \sim 3.77 \%$ ，抽穗期叶面积指数分别高 $2.76 \%$ $2.93 \% 、 1.08 \% \sim 1.47 \%$ ，成熟期叶面积指数分别高

表 4 角优系列籼粳杂交稻各生育阶段物质积累及其比例的差异

Table 4 Differences in dry matter accumulation and its ratio at main growing stages of indica-japonica hybrid rice varieties of Yongyou series

\begin{tabular}{|c|c|c|c|c|c|c|c|c|c|}
\hline \multirow[b]{2}{*}{$\begin{array}{c}\text { 品种类型 } \\
\text { Type }\end{array}$} & \multirow[b]{2}{*}{$\begin{array}{c}\text { 品种名称 } \\
\text { Variety }\end{array}$} & \multicolumn{2}{|c|}{ 移栽-拔节 $\mathrm{T}-\mathrm{J}$} & \multicolumn{2}{|c|}{ 拔节-抽穗 J-H } & \multicolumn{2}{|c|}{ 抽穗-成熟 $\mathrm{H}-\mathrm{M}$} & \multirow{2}{*}{$\begin{array}{c}\text { 群体总 } \\
\text { 干物重 } \\
\text { Total dry } \\
\text { matter } \\
\text { accumulation } \\
\left(\mathrm{t} \mathrm{hm}^{-2}\right) \\
\end{array}$} & \multirow[b]{2}{*}{$\begin{array}{c}\text { 收获指数 } \\
\text { Harvest } \\
\text { index }\end{array}$} \\
\hline & & $\begin{array}{c}\text { 积累量 } \\
\text { Accumulate } \\
\left(\mathrm{t} \mathrm{hm}^{-2}\right)\end{array}$ & $\begin{array}{c}\text { 比例 } \\
\text { RBT } \\
(\%)\end{array}$ & $\begin{array}{c}\text { 积累量 } \\
\text { Accumulate } \\
\left(\mathrm{t} \mathrm{hm}^{-2}\right)\end{array}$ & $\begin{array}{c}\text { 比例 } \\
\text { RBT } \\
(\%)\end{array}$ & $\begin{array}{c}\text { 积累量 } \\
\text { Accumulate } \\
\left(\mathrm{t} \mathrm{hm}^{-2}\right)\end{array}$ & $\begin{array}{l}\text { 比例 } \\
\text { RBT } \\
(\%)\end{array}$ & & \\
\hline \multicolumn{10}{|l|}{2017} \\
\hline 高产氮高效 & 角优 1662 Yongyou 1662 & 4.62 & 21.82 & 8.60 & 40.56 & 7.97 & 37.62 & 21.19 & 0.5251 \\
\hline $\mathrm{HH}$ & 甬优 4949 Yongyou 4949 & 4.67 & 22.11 & 8.59 & 40.71 & 7.85 & 37.17 & 21.11 & 0.5226 \\
\hline 高产氮中效 & 角优 2640 Yongyou 2640 & 4.73 & 22.81 & 8.40 & 40.55 & 7.59 & 36.64 & 20.72 & 0.5160 \\
\hline $\mathrm{HM}$ & 甬优 4953 Yongyou 4953 & 4.70 & 22.64 & 8.54 & 41.13 & 7.53 & 36.23 & 20.77 & 0.5112 \\
\hline 中产氮中效 & 角优 6715 Yongyou 6715 & 5.00 & 25.42 & 8.13 & 41.33 & 6.54 & 33.25 & 19.67 & 0.4964 \\
\hline \multirow[t]{4}{*}{$\mathrm{MM}$} & 角优 6760 Yongyou 6760 & 4.95 & 25.28 & 8.10 & 41.33 & 6.54 & 33.39 & 19.59 & 0.4978 \\
\hline & $\mathrm{HH}$ 平均值 $\mathrm{HH}$ mean & $4.64 \mathrm{~b}$ & $21.97 \mathrm{~b}$ & $8.60 \mathrm{a}$ & $40.63 \mathrm{a}$ & $7.91 \mathrm{a}$ & $37.40 \mathrm{a}$ & $21.15 \mathrm{a}$ & $0.5239 \mathrm{a}$ \\
\hline & $\mathrm{HM}$ 平均值 $\mathrm{HM}$ mean & $4.72 \mathrm{~b}$ & $22.73 \mathrm{~b}$ & $8.47 \mathrm{a}$ & $40.84 \mathrm{a}$ & $7.56 \mathrm{~b}$ & $36.44 \mathrm{a}$ & $20.75 \mathrm{~b}$ & $0.5136 \mathrm{ab}$ \\
\hline & $\mathrm{MM}$ 平均值 $\mathrm{MM}$ mean & $4.97 \mathrm{a}$ & $25.35 \mathrm{a}$ & $8.11 \mathrm{~b}$ & $41.33 \mathrm{a}$ & $6.54 \mathrm{c}$ & $33.32 \mathrm{~b}$ & $19.63 \mathrm{c}$ & $0.4971 \mathrm{~b}$ \\
\hline \multicolumn{10}{|l|}{2018} \\
\hline 高产氮高效 & 角优 1662 Yongyou 1662 & 4.82 & 22.45 & 8.64 & 40.22 & 8.02 & 37.33 & 21.48 & 0.5218 \\
\hline $\mathrm{HH}$ & 角优 4949 Yongyou 4949 & 4.79 & 22.36 & 8.68 & 40.49 & 7.97 & 37.16 & 21.44 & 0.5213 \\
\hline 高产氮中效 & 角优 2640 Yongyou 2640 & 4.81 & 23.19 & 8.59 & 41.42 & 7.34 & 35.39 & 20.74 & 0.5192 \\
\hline $\mathrm{HM}$ & 角优 4953 Yongyou 4953 & 4.85 & 23.27 & 8.52 & 40.91 & 7.46 & 35.82 & 20.83 & 0.5121 \\
\hline 中产氮中效 & 角优 6715 Yongyou 6715 & 5.11 & 25.93 & 8.19 & 41.54 & 6.41 & 32.54 & 19.71 & 0.5018 \\
\hline \multirow[t]{4}{*}{ MM } & 角优 6760 Yongyou 6760 & 5.17 & 26.26 & 8.07 & 40.97 & 6.45 & 32.77 & 19.69 & 0.5002 \\
\hline & $\mathrm{HH}$ 平均值 $\mathrm{HH}$ mean & $4.80 \mathrm{~b}$ & $22.41 \mathrm{c}$ & $8.66 \mathrm{a}$ & $40.35 \mathrm{a}$ & $7.99 \mathrm{a}$ & $37.24 \mathrm{a}$ & $21.46 \mathrm{a}$ & $0.5216 \mathrm{a}$ \\
\hline & $\mathrm{HM}$ 平均值 $\mathrm{HM}$ mean & $4.83 \mathrm{~b}$ & $23.23 \mathrm{~b}$ & $8.56 \mathrm{a}$ & $41.17 \mathrm{a}$ & $7.40 \mathrm{~b}$ & $35.60 \mathrm{~b}$ & $20.78 b$ & $0.5156 \mathrm{a}$ \\
\hline & $\mathrm{MM}$ 平均值 $\mathrm{MM}$ mean & $5.14 \mathrm{a}$ & $26.09 \mathrm{a}$ & $8.13 \mathrm{~b}$ & $41.26 \mathrm{a}$ & $6.43 \mathrm{c}$ & $32.65 \mathrm{c}$ & $19.70 \mathrm{c}$ & $0.5010 \mathrm{~b}$ \\
\hline
\end{tabular}

同一类型同一列数据后不同小写字母表示在 0.05 水平下差异显著。

Within a column for the same variety type, values followed by different small letters are significantly different at the 0.05 probability level. T: transplanting; J: jointing; H: heading; M: maturity; RBT: ratio of biomass to total; HH: high yield and high agronomic nitrogen use efficiency; HM: high yield and medium agronomic nitrogen use efficiency; MM: medium yield and medium agronomic nitrogen use efficiency. 
表 5 角优系列籼粳杂交稻各生育期叶面积指数和结实期叶面积衰减率的差异

Table 5 Differences in leaf area index and decreasing rate of leaf area at grain-filling stage of indica-japonica hybrid rice varieties of Yongyou series

\begin{tabular}{|c|c|c|c|c|c|}
\hline \multirow{2}{*}{$\begin{array}{c}\text { 品种类型 } \\
\text { Type }\end{array}$} & \multirow{2}{*}{$\begin{array}{l}\text { 品种名称 } \\
\text { Variety }\end{array}$} & \multicolumn{3}{|c|}{ 叶面积指数 LAI } & \multirow{2}{*}{$\begin{array}{c}\text { 结实期叶面积衰减率 } \\
\left.\text { DRLA (LAI d }{ }^{-1}\right)\end{array}$} \\
\hline & & 拔节期 Jointing & 抽穗期 Heading & 成熟期 Maturity & \\
\hline \multicolumn{6}{|l|}{2017} \\
\hline 高产氮高效 & 角优 1662 Yongyou 1662 & 4.33 & 8.44 & 3.89 & 0.0771 \\
\hline $\mathrm{HH}$ & 角优 4949 Yongyou 4949 & 4.35 & 8.42 & 3.84 & 0.0790 \\
\hline 高产氮中效 & 甬优 2640 Yongyou 2640 & 4.41 & 8.29 & 3.72 & 0.0816 \\
\hline HM & 角优 4953 Yongyou 4953 & 4.37 & 8.32 & 3.75 & 0.0816 \\
\hline 中产氮中效 & 角优 6715 Yongyou 6715 & 4.55 & 8.21 & 3.51 & 0.0940 \\
\hline \multirow[t]{4}{*}{ MM } & 甬优 6760 Yongyou 6760 & 4.49 & 8.18 & 3.49 & 0.0938 \\
\hline & $\mathrm{HH}$ 平均值 $\mathrm{HH}$ mean & $4.34 \mathrm{~b}$ & $8.43 \mathrm{a}$ & $3.87 \mathrm{a}$ & $0.0780 \mathrm{c}$ \\
\hline & $\mathrm{HM}$ 平均值 $\mathrm{HM}$ mean & $4.39 \mathrm{~b}$ & $8.31 \mathrm{~b}$ & $3.73 \mathrm{~b}$ & $0.0816 \mathrm{~b}$ \\
\hline & $\mathrm{MM}$ 平均值 $\mathrm{MM}$ mean & $4.52 \mathrm{a}$ & $8.19 \mathrm{c}$ & $3.50 \mathrm{c}$ & $0.0939 \mathrm{a}$ \\
\hline \multicolumn{6}{|l|}{2018} \\
\hline 高产氮高效 & 甬优 1662 Yongyou 1662 & 4.39 & 8.53 & 3.88 & 0.0816 \\
\hline $\mathrm{HH}$ & 甬优 4949 Yongyou 4949 & 4.37 & 8.57 & 3.81 & 0.0821 \\
\hline 高产氮中效 & 角优 2640 Yongyou 2640 & 4.32 & 8.43 & 3.75 & 0.0836 \\
\hline $\mathrm{HM}$ & 角优 4953 Yongyou 4953 & 4.35 & 8.39 & 3.79 & 0.0807 \\
\hline 中产氮中效 & 角优 6715 Yongyou 6715 & 4.49 & 8.34 & 3.45 & 0.0959 \\
\hline \multirow[t]{4}{*}{ MM } & 角优 6760 Yongyou 6760 & 4.52 & 8.31 & 3.46 & 0.0951 \\
\hline & $\mathrm{HH}$ 平均值 $\mathrm{HH}$ mean & $4.38 \mathrm{~b}$ & $8.55 \mathrm{a}$ & $3.85 \mathrm{a}$ & $0.0818 \mathrm{~b}$ \\
\hline & $\mathrm{HM}$ 平均值 $\mathrm{HM}$ mean & $4.34 \mathrm{~b}$ & $8.41 \mathrm{~b}$ & $3.77 \mathrm{a}$ & $0.0821 \mathrm{~b}$ \\
\hline & $\mathrm{MM}$ 平均值 $\mathrm{MM}$ mean & $4.51 \mathrm{a}$ & $8.32 \mathrm{~b}$ & $3.45 \mathrm{~b}$ & $0.0955 \mathrm{a}$ \\
\hline
\end{tabular}

同一类型同一列数据后不同小写字母表示在 0.05 水平下差异显著。

Within a column for the same variety type, values followed by different small letters are significantly different at the 0.05 probability level. LAI: leaf area index; DRLA: decreasing rate of leaf area; HH: high yield and high agronomic nitrogen use efficiency; HM: high yield and medium agronomic nitrogen use efficiency; MM: medium yield and medium agronomic nitrogen use efficiency.

$10.57 \% \sim 11.59 \%$ 、 $6.57 \% \sim 9.28 \%$ 。高产氮高效型和 高产氮中效型结实期叶面积衰减率显著低于中产 氮中效型，分别低 $14.35 \%$ 16.93\%、13.10\% $14.03 \%$ 。

2.5 不同类型角优系列籼粳杂交稻光合势、群体 生长率及净同化率的差异

与中产氮中效型相比(表 6), 高产氮高效型和高
产氮中效型移栽一拔节期光合势、群体生长率和净 同化率均低; 拔节一抽穗期群体生长率分别高 $12.68 \% \sim 18.07 \% 、 11.30 \% \sim 12.07 \%$, 净同化率分别高 $12.45 \% \sim 18.32 \% 、 12.80 \% \sim 12.88 \%$, 有显著差异; 抽 穗一成熟期光合势分别高 $18.63 \%$ 21.79\%、14.16\% $14.54 \%$ ，群体生长率分别高 $4.32 \% \sim 10.23 \% 、 3.89 \%$ $4.09 \%$, 差异显著。

表 6 角优系列籼粳杂交稻光合势、群体生长率及净同化率的差异

Table 6 Differences in photosynthetic potential, crop growth rate and net assimilation rate of indica-japonica hybrid rice varieties of Yongyou series

\begin{tabular}{|c|c|c|c|c|c|c|c|c|c|c|}
\hline \multirow{3}{*}{$\begin{array}{l}\text { 品种类型 } \\
\text { Type }\end{array}$} & \multirow{3}{*}{$\begin{array}{l}\text { 品种名称 } \\
\text { Variety }\end{array}$} & \multicolumn{3}{|c|}{$\begin{array}{l}\text { 光合势 Photosynthetic potential } \\
\qquad\left(\mathrm{m}^{2} \mathrm{~d} \mathrm{~m}^{-2}\right)\end{array}$} & \multicolumn{3}{|c|}{$\begin{array}{l}\text { 群体生长率 Crop growth rate } \\
\qquad\left(\mathrm{g} \mathrm{m}^{-2} \mathrm{~d}^{-1}\right)\end{array}$} & \multicolumn{3}{|c|}{$\begin{array}{l}\text { 净同化率 Net assimilation rate } \\
\qquad\left(\mathrm{g} \mathrm{m}^{-2} \mathrm{~d}^{-1}\right)\end{array}$} \\
\hline & & \multicolumn{3}{|c|}{ 移栽-拔节 拔节一抽穗 抽穗-成熟 } & \multicolumn{3}{|c|}{ 移栽-拔节拔节-抽穗抽穗-成熟 } & \multicolumn{3}{|c|}{ 移栽-拔节拔节-抽穗抽穗-成熟 } \\
\hline & & $\mathrm{T}-\mathrm{J}$ & $\mathrm{J}-\mathrm{H}$ & $\mathrm{H}-\mathrm{M}$ & $\mathrm{T}-\mathrm{J}$ & $\mathrm{J}-\mathrm{H}$ & $\mathrm{H}-\mathrm{M}$ & $\mathrm{T}-\mathrm{J}$ & $\mathrm{J}-\mathrm{H}$ & $\mathrm{H}-\mathrm{M}$ \\
\hline \multicolumn{11}{|l|}{2017} \\
\hline $\begin{array}{c}\text { 高产氮高效 } \\
\text { HH }\end{array}$ & $\begin{array}{c}\text { 角优 } 1662 \\
\text { Yongyou } 1662\end{array}$ & 103.92 & 166.01 & 363.74 & 9.63 & 33.07 & 13.51 & 3.26 & 5.37 & 2.30 \\
\hline
\end{tabular}


(续表 6)

\begin{tabular}{|c|c|c|c|c|c|c|c|c|c|c|}
\hline \multirow{3}{*}{$\begin{array}{c}\text { 品种类型 } \\
\text { Type }\end{array}$} & \multirow{3}{*}{$\begin{array}{c}\text { 品种名称 } \\
\text { Variety }\end{array}$} & \multicolumn{3}{|c|}{$\begin{array}{l}\text { 光合势 Photosynthetic potential } \\
\qquad\left(\mathrm{m}^{2} \mathrm{~d} \mathrm{~m}^{-2}\right) \\
\end{array}$} & \multicolumn{3}{|c|}{$\begin{array}{c}\text { 群体生长率 Crop growth rate } \\
\qquad\left(\mathrm{g} \mathrm{m}^{-2} \mathrm{~d}^{-1}\right) \\
\end{array}$} & \multicolumn{3}{|c|}{$\begin{array}{c}\text { 净同化率 Net assimilation rate } \\
\qquad\left(\mathrm{g} \mathrm{m}^{-2} \mathrm{~d}^{-1}\right) \\
\end{array}$} \\
\hline & & \multicolumn{3}{|c|}{ 移栽-拔节 拔节-抽穗 抽穗-成熟 } & \multicolumn{3}{|c|}{ 移栽-拔节 拔节-抽穗 抽穗-成熟 } & \multicolumn{3}{|c|}{ 移栽-拔节拔节-抽穗抽穗-成熟 } \\
\hline & & $\mathrm{T}-\mathrm{J}$ & $\mathrm{J}-\mathrm{H}$ & $\mathrm{H}-\mathrm{M}$ & $\mathrm{T}-\mathrm{J}$ & $\mathrm{J}-\mathrm{H}$ & $\mathrm{H}-\mathrm{M}$ & $\mathrm{T}-\mathrm{J}$ & $\mathrm{J}-\mathrm{H}$ & $\mathrm{H}-\mathrm{M}$ \\
\hline \multirow{3}{*}{$\begin{array}{c}\text { 高产氮中效 } \\
\text { HM }\end{array}$} & 角优 4949 & 106.58 & 166.01 & 355.54 & 9.52 & 33.05 & 13.53 & 3.22 & 5.36 & 2.32 \\
\hline & $\begin{array}{c}\text { Yongyou } 4949 \\
\text { 角优 } 2640 \\
\text { Yongyou } 2640\end{array}$ & 108.05 & 171.45 & 336.28 & 9.64 & 31.11 & 13.55 & 3.25 & 5.06 & 2.38 \\
\hline & $\begin{array}{c}\text { 角优 } 4953 \\
\text { Yongyou } 4953\end{array}$ & 107.07 & 171.32 & 337.96 & 9.60 & 31.65 & 13.44 & 3.24 & 5.16 & 2.34 \\
\hline \multirow[t]{5}{*}{$\begin{array}{c}\text { 中产氮中效 } \\
\mathrm{MM}\end{array}$} & $\begin{array}{c}\text { 角优 } 6715 \\
\text { Yongyou } 6715\end{array}$ & 116.03 & 185.02 & 293.00 & 9.81 & 28.05 & 13.09 & 3.27 & 4.52 & 2.37 \\
\hline & $\begin{array}{c}\text { 角优 } 6760 \\
\text { Yongyou } 6760\end{array}$ & 112.25 & 183.72 & 297.59 & 9.91 & 27.94 & 12.83 & 3.31 & 4.54 & 2.33 \\
\hline & $\begin{array}{r}\mathrm{HH} \text { 平均值 } \\
\mathrm{HH} \text { mean }\end{array}$ & 105.25 a & $166.01 \mathrm{c}$ & 359.64 a & $9.57 \mathrm{a}$ & 33.06 a & 13.52 a & $3.24 \mathrm{a}$ & $5.36 \mathrm{a}$ & $2.31 \mathrm{a}$ \\
\hline & $\begin{array}{l}\mathrm{HM} \text { 平均值 } \\
\mathrm{HM} \text { mean }\end{array}$ & $107.56 \mathrm{a}$ & $171.38 \mathrm{~b}$ & $337.12 \mathrm{~b}$ & $9.62 \mathrm{a}$ & $31.38 \mathrm{~b}$ & 13.49 a & $3.24 \mathrm{a}$ & $5.11 \mathrm{~b}$ & $2.36 \mathrm{a}$ \\
\hline & $\begin{array}{r}\mathrm{MM} \text { 平均值 } \\
\mathrm{MM} \text { mean }\end{array}$ & $114.14 \mathrm{a}$ & 184.37 a & 295.30 c & $9.86 \mathrm{a}$ & $28.00 \mathrm{c}$ & $12.96 \mathrm{~b}$ & $3.29 \mathrm{a}$ & $4.53 \mathrm{c}$ & $2.35 \mathrm{a}$ \\
\hline \multicolumn{11}{|l|}{2018} \\
\hline \multirow[t]{2}{*}{$\begin{array}{c}\text { 高产氮高效 } \\
\text { HH }\end{array}$} & $\begin{array}{c}\text { 角优 } 1662 \\
\text { Yongyou } 1662\end{array}$ & 107.56 & 174.42 & 353.69 & 9.84 & 32.00 & 14.07 & 3.32 & 5.13 & 2.38 \\
\hline & $\begin{array}{c}\text { 角优 } 4949 \\
\text { Yongyou } 4949\end{array}$ & 107.07 & 168.22 & 359.02 & 9.79 & 33.40 & 13.74 & 3.30 & 5.36 & 2.34 \\
\hline \multirow[t]{2}{*}{$\begin{array}{c}\text { 高产氮中效 } \\
\mathrm{HM}\end{array}$} & $\begin{array}{c}\text { 角优 } 2640 \\
\text { Yongyou } 2640\end{array}$ & 105.84 & 172.13 & 341.04 & 9.82 & 31.82 & 13.11 & 3.33 & 5.18 & 2.27 \\
\hline & $\begin{array}{c}\text { 角优 } 4953 \\
\text { Yongyou } 4953\end{array}$ & 106.58 & 165.62 & 347.13 & 9.89 & 32.78 & 13.10 & 3.34 & 5.33 & 2.26 \\
\hline \multirow[t]{5}{*}{$\begin{array}{c}\text { 中产氮中效 } \\
\text { MM }\end{array}$} & $\begin{array}{c}\text { 角优 } 6715 \\
\text { Yongyou } 6715\end{array}$ & 114.50 & 179.62 & 300.65 & 10.02 & 29.24 & 12.57 & 3.35 & 4.70 & 2.27 \\
\hline & $\begin{array}{c}\text { 角优 } 6760 \\
\text { Yongyou } 6760\end{array}$ & 115.26 & 179.62 & 300.14 & 10.14 & 28.81 & 12.65 & 3.38 & 4.63 & 2.29 \\
\hline & $\begin{array}{r}\mathrm{HH} \text { 平均值 } \\
\mathrm{HH} \text { mean }\end{array}$ & $107.32 \mathrm{~b}$ & $171.32 \mathrm{a}$ & 356.36 a & $9.81 \mathrm{a}$ & 32.70 a & 13.90 a & $3.31 \mathrm{a}$ & $5.24 \mathrm{a}$ & $2.36 \mathrm{a}$ \\
\hline & $\begin{array}{c}\text { HM 平均值 } \\
\text { HM mean }\end{array}$ & $106.21 \mathrm{~b}$ & 168.88 a & $344.08 \mathrm{~b}$ & $9.85 \mathrm{a}$ & 32.30 a & $13.10 \mathrm{~b}$ & $3.34 \mathrm{a}$ & $5.26 \mathrm{a}$ & $2.27 \mathrm{~b}$ \\
\hline & $\begin{array}{l}\text { MM 平均值 } \\
\text { MM mean }\end{array}$ & 114.88 a & 179.62 a & 300.39 c & 10.08 a & $29.02 \mathrm{~b}$ & $12.61 \mathrm{~b}$ & 3.37 a & $4.66 \mathrm{~b}$ & $2.28 \mathrm{ab}$ \\
\hline
\end{tabular}

同一类型同一列数据后不同小写字母表示在 0.05 水平下差异显著。

Within a column for the same variety type, values followed by different small letters are significantly different at the 0.05 probability level. T: transplanting; J: jointing; H: heading; M: maturity; HH: high yield and high agronomic nitrogen use efficiency; HM: high yield and medium agronomic nitrogen use efficiency; MM: medium yield and medium agronomic nitrogen use efficiency.

2.6 不同类型角优系列籼粳杂交稻各生育阶段 氮素积累量及比例和吸收速率的差异

与高产氮中效型相比(表 7), 高产氮高效型拔 节一抽穗期氮素积累量、积累比例和吸收速率分别 高 7.74\% 8.31\%、2.53\% 3.01\%和 7.79\% 12.33\%, 差 异显著; 抽穗一成熟期氮素积累量、吸收速率以及 总吸氮量分别高 $11.92 \%$ 12.01\%、6.58\% 10.53\%和 $5.07 \%$ 5.14\%, 除 2017 年抽穗一成熟期氮素积累量,
均有显著差异。

与中产氮中效型相比, 高产氮高效型移栽一拔 节期氮素积累量、积累比例和吸收速率均较低; 拔 节一抽穗期氮素积累量和吸收速率分别高 $6.25 \%$ 6.95\%、13.08\% 18.36\%，差异显著；抽穗一成熟期 氮素积累量、积累比例和吸收速率分别高 $34.90 \% \sim 43.80 \% 、 29.25 \% \sim 35.67 \%$ 和 15.71\% 27.27\%, 有显著差异; 总吸氮量高 4.50\% 5.96\%, 差异显著。 


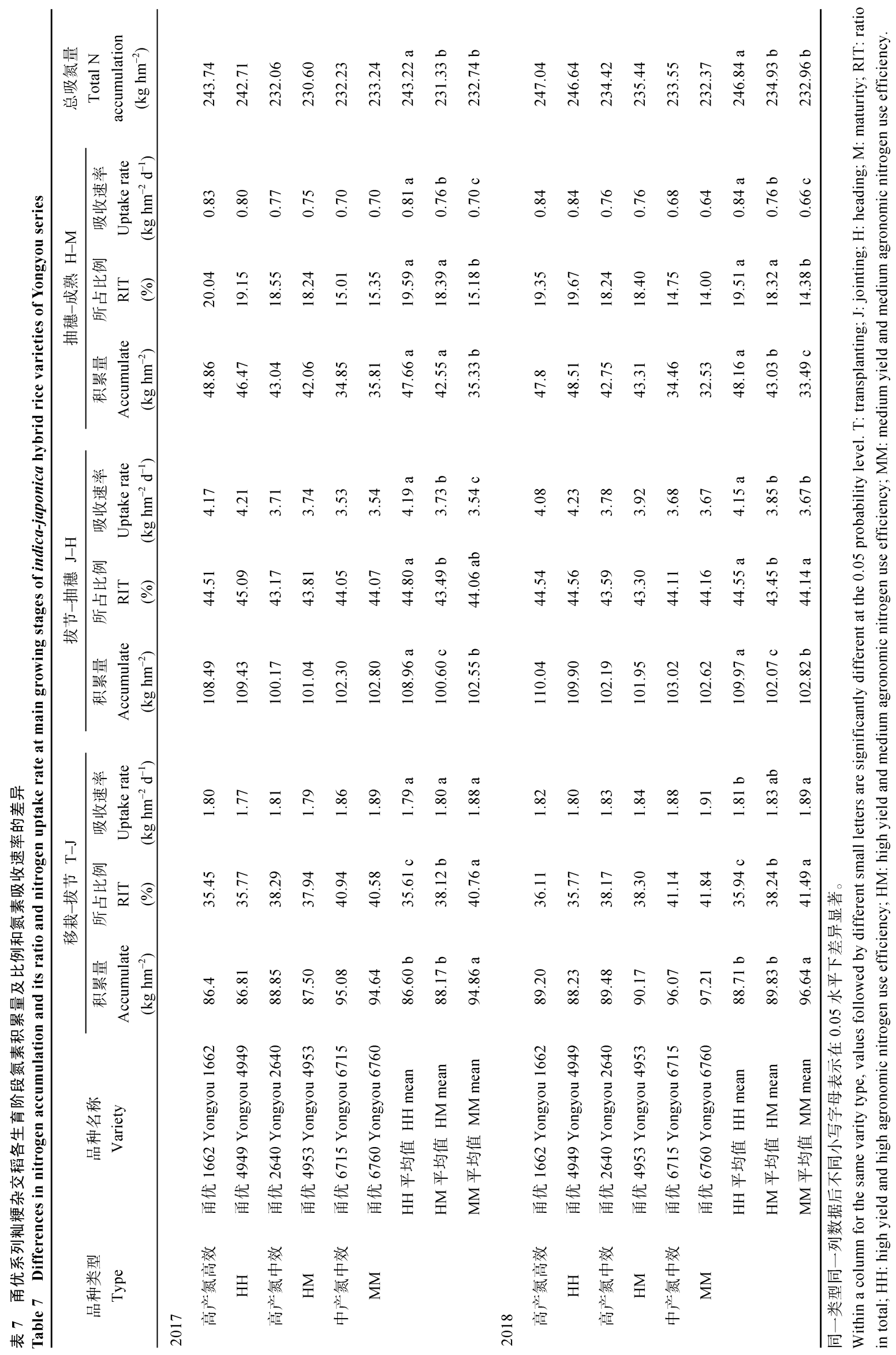


2.7 不同类型角优系列籼粳杂交稻抽穗一成熟 期各器官氮素积累及转运的差异

与高产氮中效型相比(表 8), 高产氮高效型花后
茎鞘氮素转运量、穗部氮素积累量和氮素收获指数 分别高 $26.13 \% \sim 31.51 \% 、 9.80 \% \sim 11.05 \%$ 和 $3.93 \%$ 4.58\%，差异显著。

表 8 角优系列籼粳杂交稻抽穗期和成熟期各器官氮素积累和转运的差异

Table 8 Differences in $\mathrm{N}$ accumulate and transportation in each organ at heading and maturity of indica-japonica hybrid rice varieties of Yongyou series

\begin{tabular}{|c|c|c|c|c|c|c|c|c|c|c|c|}
\hline \multirow{3}{*}{$\begin{array}{c}\text { 品种类型 } \\
\text { Type }\end{array}$} & \multirow{3}{*}{$\begin{array}{c}\text { 品种名称 } \\
\text { Variety }\end{array}$} & \multicolumn{6}{|c|}{ 氮素积累量 Nitrogen accumulation $\left(\mathrm{kg} \mathrm{hm}^{-2}\right)$} & \multirow{3}{*}{$\begin{array}{c}\text { 茎鞘 } \\
\text { 氮素转 } \\
\text { 运量 } \\
\text { NTSH } \\
\left(\mathrm{kg} \mathrm{hm}^{-2}\right) \\
\end{array}$} & \multirow{3}{*}{$\begin{array}{c}\text { 叶片 } \\
\text { 氮素转 } \\
\text { 运量 } \\
\text { NTLH } \\
\left(\mathrm{kg} \mathrm{hm}^{-2}\right) \\
\end{array}$} & \multirow{3}{*}{$\begin{array}{c}\text { 穗部 } \\
\text { 氮素积 } \\
\text { 累量 } \\
\text { NIPH } \\
\left(\mathrm{kg} \mathrm{hm}^{-2}\right) \\
\end{array}$} & \multirow{3}{*}{$\begin{array}{c}\text { 氮素 } \\
\text { 收获指数 } \\
\text { NHI } \\
(\%) \\
\end{array}$} \\
\hline & & \multicolumn{3}{|c|}{ 抽穗期 Heading } & \multicolumn{3}{|c|}{ 成熟期 Maturity } & & & & \\
\hline & & $\begin{array}{l}\text { 茎鞘 } \\
\text { Stem }\end{array}$ & $\begin{array}{l}\text { 叶片 } \\
\text { Leaf }\end{array}$ & $\begin{array}{c}\text { 穗部 } \\
\text { Panicle }\end{array}$ & $\begin{array}{l}\text { 茎鞘 } \\
\text { Stem }\end{array}$ & $\begin{array}{l}\text { 叶片 } \\
\text { Leaf }\end{array}$ & $\begin{array}{c}\text { 穗部 } \\
\text { Panicle }\end{array}$ & & & & \\
\hline \multicolumn{12}{|l|}{2017} \\
\hline \multirow[t]{2}{*}{$\begin{array}{c}\text { 高产氮高效 } \\
\text { HH }\end{array}$} & $\begin{array}{c}\text { 角优 } 1662 \\
\text { Yongyou } 1662\end{array}$ & 70.87 & 95.14 & 28.88 & 42.27 & 43.62 & 157.85 & 28.60 & 51.52 & 128.97 & 64.76 \\
\hline & $\begin{array}{c}\text { 角优 } 4949 \\
\text { Yongyou } 4949\end{array}$ & 71.38 & 97.14 & 27.72 & 43.13 & 43.92 & 155.66 & 28.25 & 53.22 & 127.94 & 64.13 \\
\hline \multirow[t]{2}{*}{$\begin{array}{c}\text { 高产氮中效 } \\
\text { HM }\end{array}$} & $\begin{array}{c}\text { 角优 } 2640 \\
\text { Yongyou } 2640\end{array}$ & 69.26 & 93.81 & 25.95 & 47.44 & 42.55 & 142.06 & 21.82 & 51.26 & 116.11 & 61.22 \\
\hline & $\begin{array}{c}\text { 角优 } 4953 \\
\text { Yongyou } 4953\end{array}$ & 67.00 & 93.78 & 27.75 & 45.60 & 41.98 & 143.01 & 21.40 & 51.80 & 115.26 & 62.02 \\
\hline \multirow[t]{5}{*}{$\begin{array}{c}\text { 中产氮中效 } \\
\mathrm{MM}\end{array}$} & $\begin{array}{l}\text { 角优 } 6715 \\
\text { Yongyou } 6715\end{array}$ & 72.28 & 99.37 & 25.73 & 55.49 & 47.47 & 129.27 & 16.79 & 51.90 & 103.54 & 55.66 \\
\hline & $\begin{array}{c}\text { 角优 } 6760 \\
\text { Yongyou } 6760\end{array}$ & 73.57 & 98.92 & 24.94 & 57.59 & 47.87 & 127.78 & 15.98 & 51.05 & 102.84 & 54.78 \\
\hline & $\begin{array}{r}\mathrm{HH} \text { 平均值 } \\
\mathrm{HH} \text { mean }\end{array}$ & $71.13 \mathrm{a}$ & $96.14 \mathrm{ab}$ & $28.30 \mathrm{a}$ & $42.70 \mathrm{~b}$ & $43.77 \mathrm{~b}$ & $156.76 \mathrm{a}$ & $28.42 \mathrm{a}$ & $52.37 \mathrm{a}$ & $128.46 \mathrm{a}$ & $64.44 \mathrm{a}$ \\
\hline & $\begin{array}{r}\mathrm{HM} \text { 平均值 } \\
\mathrm{HM} \text { mean }\end{array}$ & $68.13 \mathrm{a}$ & $93.80 \mathrm{~b}$ & $26.85 \mathrm{a}$ & $46.52 \mathrm{~b}$ & $42.26 \mathrm{~b}$ & $142.54 \mathrm{~b}$ & $21.61 \mathrm{~b}$ & $51.53 \mathrm{a}$ & $115.68 \mathrm{~b}$ & $61.62 \mathrm{~b}$ \\
\hline & $\begin{array}{c}M M \text { 平均值 } \\
M M \text { mean }\end{array}$ & $72.93 \mathrm{a}$ & $99.14 \mathrm{a}$ & $25.33 \mathrm{a}$ & $56.54 \mathrm{a}$ & $47.67 \mathrm{a}$ & $128.52 \mathrm{c}$ & $16.39 \mathrm{c}$ & $51.47 \mathrm{a}$ & $103.19 \mathrm{c}$ & $55.22 \mathrm{c}$ \\
\hline \multicolumn{12}{|l|}{2018} \\
\hline \multirow[t]{2}{*}{$\begin{array}{c}\text { 高产氮高效 } \\
\text { HH }\end{array}$} & $\begin{array}{c}\text { 角优 } 1662 \\
\text { Yongyou } 1662\end{array}$ & 74.53 & 96.20 & 28.50 & 46.45 & 46.67 & 153.92 & 28.08 & 49.53 & 125.42 & 62.31 \\
\hline & $\begin{array}{c}\text { 角优 } 4949 \\
\text { Yongyou } 4949\end{array}$ & 73.50 & 96.83 & 27.79 & 45.87 & 45.69 & 155.08 & 27.63 & 51.14 & 127.29 & 62.88 \\
\hline \multirow[t]{2}{*}{$\begin{array}{c}\text { 高产氮中效 } \\
\text { HM }\end{array}$} & $\begin{array}{c}\text { 角优 } 2640 \\
\text { Yongyou } 2640\end{array}$ & 69.68 & 95.04 & 26.95 & 48.43 & 44.24 & 141.74 & 21.25 & 50.80 & 114.79 & 60.47 \\
\hline & $\begin{array}{c}\text { 角优 } 4953 \\
\text { Yongyou } 4953\end{array}$ & 71.99 & 94.27 & 25.87 & 49.08 & 45.11 & 141.25 & 22.91 & 49.16 & 115.38 & 59.99 \\
\hline \multirow[t]{5}{*}{$\begin{array}{c}\text { 中产氮中效 } \\
\mathrm{MM}\end{array}$} & $\begin{array}{c}\text { 角优 } 6715 \\
\text { Yongyou } 6715\end{array}$ & 72.31 & 101.00 & 25.78 & 57.10 & 50.30 & 126.15 & 15.21 & 50.70 & 100.37 & 54.01 \\
\hline & $\begin{array}{c}\text { 角优 } 6760 \\
\text { Yongyou } 6760\end{array}$ & 73.47 & 101.24 & 25.12 & 57.75 & 49.73 & 124.89 & 15.72 & 51.51 & 99.77 & 53.75 \\
\hline & $\begin{array}{c}\mathrm{HH} \text { 平均值 } \\
\mathrm{HH} \text { mean }\end{array}$ & $74.02 \mathrm{a}$ & $96.52 \mathrm{~b}$ & $28.15 \mathrm{a}$ & $46.16 \mathrm{c}$ & $46.18 \mathrm{~b}$ & $154.50 \mathrm{a}$ & $27.85 \mathrm{a}$ & $50.33 \mathrm{a}$ & $126.36 \mathrm{a}$ & $62.60 \mathrm{a}$ \\
\hline & $\begin{array}{c}\mathrm{HM} \text { 平均值 } \\
\mathrm{HM} \text { mean }\end{array}$ & $70.84 \mathrm{a}$ & $94.65 \mathrm{~b}$ & $26.41 \mathrm{~b}$ & $48.76 \mathrm{~b}$ & $44.67 \mathrm{~b}$ & $141.49 \mathrm{~b}$ & $22.08 \mathrm{~b}$ & $49.98 \mathrm{a}$ & $115.08 \mathrm{~b}$ & $60.23 \mathrm{~b}$ \\
\hline & $\begin{array}{c}M M \text { 平均值 } \\
\text { MM mean }\end{array}$ & $72.89 \mathrm{a}$ & $101.12 \mathrm{a}$ & $25.45 \mathrm{c}$ & $57.42 \mathrm{a}$ & $50.01 \mathrm{a}$ & $125.52 \mathrm{c}$ & $15.47 \mathrm{c}$ & $51.10 \mathrm{a}$ & $100.07 \mathrm{c}$ & $53.88 \mathrm{c}$ \\
\hline
\end{tabular}

同一类型同一列数据后不同小写字母表示在 0.05 水平下差异显著。

Within a column for the same variety type, values followed by different small letters are significantly different at the 0.05 probability level. NTLH: $\mathrm{N}$ transportation from leaf after heading; NTSH: $\mathrm{N}$ transportation from stem after heading; NIPH: $\mathrm{N}$ increase in panicle after heading; NHI: N harvest index; HH: high yield and high agronomic nitrogen use efficiency; HM: high yield and medium agronomic nitrogen use efficiency; MM: medium yield and medium agronomic nitrogen use efficiency. 
与中产氮中效型相比, 高产氮高效型成熟期茎 鞘、叶片氮素积累量显著低，分别低 19.61\% 24.48\%、 $7.66 \% \sim 8.18 \%$ ，穗部氮素积累量则显著高，高 $21.97 \%$ 23.09\%; 花后茎鞘氮素转运量、穗部氮素积 累量和氮素收获指数分别高 $73.40 \%$ $80.03 \%$ 、 $24.49 \%$ 26.27\%和 $16.18 \% \sim 16.70 \%$ ，差异显著。

2.8 不同类型角优系列籼粳杂交稻氮肥利用率的差异 与高产氮中效型相比(表 9), 高产氮高效型氮素
$17.31 \% 、 2.41 \% \sim 3.08 \%$ 和 $3.98 \% \sim 4.43 \%$ ，差异显著。 与中产氮中效型相比, 高产氮高效型氮素农 学利用率、氮素生理利用率和氮肥偏生产力分别 高 $22.12 \% \sim 25.17 \%$ 、17.68\% 19.85\%和 $13.43 \%$ $13.46 \%$ ，百千克籽粒吸氮量低 $7.20 \% \sim 7.98 \%$ ，均 有显著差异。

回收利用率、氮素农学利用率、氮素生理利用 率和氮肥偏生产力分别高 $11.87 \%$ 13.83\%、14.52\%

表 9 角优系列籼粳杂交稻氮肥利用效率的差异

Table 9 Differences in nitrogen use efficiency of indica-japonica hybrid rice varieties of Yongyou series

\begin{tabular}{|c|c|c|c|c|c|c|}
\hline $\begin{array}{c}\text { 品种类型 } \\
\text { Type }\end{array}$ & $\begin{array}{c}\text { 品种名称 } \\
\text { Variety }\end{array}$ & $\begin{array}{l}\text { 氮素回收 } \\
\text { 利用率 } \\
\operatorname{NRE~}(\%) \\
\end{array}$ & $\begin{array}{c}\text { 氮素农学 } \\
\text { 利用率 } \\
\mathrm{AE}\left(\mathrm{kg} \mathrm{kg}^{-1}\right) \\
\end{array}$ & $\begin{array}{c}\text { 氮素生理 } \\
\text { 利用率 } \\
\text { PNUE }\left(\mathrm{kg} \mathrm{kg}^{-1}\right) \\
\end{array}$ & $\begin{array}{c}\text { 氮肥偏生 } \\
\text { 产力 } \\
\text { PFP }\left(\mathrm{kg} \mathrm{kg}^{-1}\right) \\
\end{array}$ & $\begin{array}{c}\text { 百千克籽粒 } \\
\text { 需氮量 } \\
\text { NRG }(\mathrm{kg}) \\
\end{array}$ \\
\hline \multicolumn{7}{|l|}{2017} \\
\hline 高产氮高效 & 角优 1662 Yongyou 1662 & 45.16 & 18.81 & 41.65 & 41.23 & 2.19 \\
\hline $\mathrm{HH}$ & 角优 4949 Yongyou 4949 & 44.22 & 18.6 & 42.05 & 40.85 & 2.2 \\
\hline 高产氮中效 & 角优 2640 Yongyou 2640 & 39.13 & 15.88 & 40.58 & 39.61 & 2.17 \\
\hline $\mathrm{HM}$ & 角优 4953 Yongyou 4953 & 39.38 & 15.99 & 40.61 & 39.34 & 2.17 \\
\hline 中产氮中效 & 角优 6715 Yongyou 6715 & 42.42 & 14.79 & 34.87 & 36.19 & 2.38 \\
\hline \multirow[t]{4}{*}{ MM } & 角优 6760 Yongyou 6760 & 43.16 & 15.09 & 34.96 & 36.15 & 2.39 \\
\hline & $\mathrm{HH}$ 平均值 $\mathrm{HH}$ mean & $44.69 \mathrm{a}$ & $18.70 \mathrm{a}$ & $41.85 \mathrm{a}$ & $41.04 \mathrm{a}$ & $2.19 \mathrm{~b}$ \\
\hline & $\mathrm{HM}$ 平均值 $\mathrm{HM}$ mean & $39.26 \mathrm{~b}$ & $15.94 \mathrm{~b}$ & $40.60 \mathrm{~b}$ & $39.47 \mathrm{~b}$ & $2.17 \mathrm{c}$ \\
\hline & $\mathrm{MM}$ 平均值 $\mathrm{MM}$ mean & $42.79 \mathrm{a}$ & $14.94 \mathrm{c}$ & $34.92 \mathrm{c}$ & $36.17 \mathrm{c}$ & $2.38 \mathrm{a}$ \\
\hline \multicolumn{7}{|l|}{2018} \\
\hline 高产氮高效 & 角优 1662 Yongyou 1662 & 43.69 & 19.18 & 43.9 & 41.5 & 2.20 \\
\hline $\mathrm{HH}$ & 角优 4949 Yongyou 4949 & 44.93 & 19.14 & 42.61 & 41.41 & 2.21 \\
\hline 高产氮中效 & 角优 2640 Yongyou 2640 & 39.91 & 16.94 & 42.44 & 39.89 & 2.18 \\
\hline $\mathrm{HM}$ & 角优 4953 Yongyou 4953 & 39.31 & 16.52 & 42.03 & 39.51 & 2.21 \\
\hline 中产氮中效 & 角优 6715 Yongyou 6715 & 42.83 & 15.94 & 37.21 & 36.63 & 2.36 \\
\hline \multirow[t]{4}{*}{ MM } & 角优 6760 Yongyou 6760 & 42.50 & 15.43 & 36.31 & 36.47 & 2.36 \\
\hline & $\mathrm{HH}$ 平均值 $\mathrm{HH}$ mean & $44.31 \mathrm{a}$ & $19.16 \mathrm{a}$ & $43.26 \mathrm{a}$ & $41.46 \mathrm{a}$ & $2.19 \mathrm{~b}$ \\
\hline & $\mathrm{HM}$ 平均值 $\mathrm{HM}$ mean & $39.61 \mathrm{~b}$ & $16.73 \mathrm{~b}$ & $42.24 \mathrm{a}$ & $39.70 \mathrm{~b}$ & $2.20 \mathrm{~b}$ \\
\hline & $\mathrm{MM}$ 平均值 $\mathrm{MM}$ mean & $42.67 \mathrm{a}$ & $15.69 \mathrm{c}$ & $36.76 \mathrm{~b}$ & $36.55 \mathrm{c}$ & $2.36 \mathrm{a}$ \\
\hline
\end{tabular}

同一类型同一列数据后不同小写字母表示在 0.05 水平下差异显著。

Within a column for the same variety type, values followed by different small letters are significantly different at the 0.05 probability level. NRE: nitrogen recovery use efficiency; AE: agronomic nitrogen use efficiency; PE: physiological nitrogen use efficiency; PFP: partial factor productivity of applied N; NRG: nitrogen requirement for $100 \mathrm{~kg}$ grain; HH: high yield and high agronomic nitrogen use efficiency; HM: high yield and medium agronomic nitrogen use efficiency; MM: medium yield and medium agronomic nitrogen use efficiency.

\section{3 讨论}

\section{1 不同类型甬优系列籼粳杂交稻产量及物质 积累的差异}

群体颖花量(单位面积穗数 $\times$ 每穗粒数)、结实率 和千粒重是构成水稻产量的基本要素。前人研究表 明 ${ }^{[7-9]}$, 群体颖花量的提高是水稻获得高产的重要途 径。吴桂成等 ${ }^{[28]}$ 以 4 个超级粳稻为材料研究发现, 高
产到更高产, 颖花量增加以穗数贡献率较高, 更高 产到超高产, 以每穗粒数的贡献率较高; 胡雅杰等 ${ }^{[9]}$ 研究发现, 从高产群体到超高产群体, 颖花量的提 高在于每穗粒数的显著增加; 花劲等 ${ }^{[8}$ 研究表明, 双季晚粳稻从高产向超高产的实现在于适当增加穗 数, 主攻大穗, 并保持较高的结实率和千粒重。本研 究结果表明, 高产氮高效型品种群体颖花量显著高 于高产氮中效型和中产氮中效型品种, 并且在大库 
容下保证了稳定适宜的结实率和千粒重，从而实现 高产。这说明，在同为籼粳杂交稻，都具有“穗大粒 多”特点的条件下, 想要获得高产的关键依然是提高 群体颖花量, 并保证一定的结实率和千粒重。

水稻产量的形成过程实质是群体干物质合成、 积累、运转与分配的过程, 增加水稻干物质生产总 量, 特别是抽穗后光合物质积累量可显著提高产量 水平 ${ }^{[29]}$ 。Wei 等 ${ }^{[30]}$ 研究表明, 籼粳杂交稻各生育期叶 面积指数、干物质积累量以及灌浆结实时间均显著 高于常规粳稻; 郭保卫等 ${ }^{[14]}$ 研究表明, 籼粳杂交稻 抽穗一成熟期光合势和群体生长率显著高于其他类 型水稻(常规粳稻、杂交粳稻和杂交籼稻); 同为籼粳 杂交稻，高产品种抽穗一成熟期干物质积累量和光 合势较高, 叶面积衰减率较低 ${ }^{[24]}$; 超高产群体抽穗 期、成熟期和抽穗一成熟期干物质积累量显著高于 高产群体 ${ }^{[7-9]}$ 。本研究中, 高产氮高效型生育前期干 物质积累量较低, 生育中期干物质积累迅速提高, 生育后期干物质积累量显著高于其他类型，其原因 在于高产氮高效型生育前期无效分菜发生少; 拔节 后分菜平稳消减, 群体结构优化, 通风透光性好, 促进了生育中后期叶片的生长，叶面积指数、光合 势和群体生长率均显著提高, 物质生产能力增强; 生育后期叶面积指数高、叶面积衰减率低，灌浆时 间较其他两种类型平均长 5 6 d, 平稳较高的叶面积 指数和较长的灌浆时间保证了生育后期稳定持久的 光合生产能力 ${ }^{[30]}$, 保证了大库容的充实。同为籼粳 杂交稻, 高产需要生育前期获得适宜的分䔄, 生育 中后期保持较大叶面积指数、光合势、群体生长率、 较强干物质生产能力和较高干物质积累量。

\section{2 不同类型角优系列籼粳杂交稻氮素吸收及} 利用的差异

水稻氮素吸收分为抽穗前和抽穗后两个阶段, 抽穗前氮素吸收量占总量 70\% 80\%, 抽穗后所占比 例较小; 前期氮素吸收量大有利于形成高产群体, 后期氮素吸氮量高有利于水稻从氮代谢向碳代谢转 变, 促进抽穗后光合产物向籽粒输送, 有利于产量 形成 ${ }^{[31]}$ 。李超等 ${ }^{[21]}$ 认为, 籼粳杂交稻拔节至抽穗期 较高的氮素积累量和吸收速率有利于颖花分化, 形 成较大的群体颖花量，促进生育后期氮素吸收; Zhang 等 ${ }^{[32]}$ 研究认为, 单位面积穗数少的水稻品种, 灌浆期对碳、氮元素需求量小, 氮素积累量低; Huang 等 ${ }^{[33]}$ 认为, 库容量大的水稻, 抽穗后氮素积 累能力强; 吴越等 ${ }^{[31]}$ 研究认为, 高产水稻抽穗至成
熟期氮素积累量高。综上所述, 单位面积穗数多, 群 体颖花量高, 库容量大以及产量高的水稻抽穗后氮 素积累量高。本研究中, 抽穗后氮素积累量表现为 高产氮高效型>高产氮中效型>中产氮中效型，这与 上述研究基本一致。韦还和等 ${ }^{[27]}$ 研究发现, 超高产 群体拔节前氮素积累量显著低于高产和更高产群体， 而拔节至抽穗期、抽穗至成熟期氮素积累量显著增 加。本研究结果表明, 中产氮中效型拔节前氮素积累 量最高, 这可能与其生育前期分䔄旺盛有关 ${ }^{[34]}$, 拔 节至抽穗期、抽穗至成熟期氮素积累量均以高产氮 高效型最高。前人研究发现 ${ }^{[21,35]}$, 水稻拔节一抽穗期 较高的氮素积累量和氮素吸收速率有利于群体颖花 量的增加。本研究中, 高产氮高效型拔节一抽穗期 氮素积累量和氮素吸收速率最高, 群体颖花量最大; 高产氮中效型拔节一抽穗期氮素积累量与中产氮中 效型相当(均值分别为 $101.34 \mathrm{~kg} \mathrm{hm}^{-2}$ 和 $102.69 \mathrm{~kg}$ $\mathrm{hm}^{-2}$ ), 但氮素吸收速率显著高, 群体颖花量显著增 加。这说明，在保证拔节一抽穗期氮素吸收量的基 础上, 提高氮素吸收速率, 有利于群体颖花量的增 加。

氮素利用效率是氮素吸收、同化、转运和再利 用等多个生理过程综合作用的结果，其通用表征指 标包括氮、素吸收利用率、农学利用率、生理利用率、 籽粒生产效率、干物质生产效率、偏生产力和收获 指数等, 这些指标从不同侧面描述了作物对氮素的 利用情况 ${ }^{[21]}$ 。提高水稻生育后期的氮素运转, 促进 氮素及非结构性碳水化合物向籽粒的转运，有利于 进一步提高稻谷产量和氮肥利用效率 ${ }^{[27]}$ 。李超等 ${ }^{[21]}$ 研究发现, 籼粳杂交稻抽穗后茎鞘氮素转运量和氮 素净积累量贡献率极显著高于常规粳稻和杂交籼稻; 韦还和等 ${ }^{[27]}$ 研究发现, 角优 12 超高产群体花后茎鞘 氮素转运量高于高产群体与更高产群体; 李敏等 ${ }^{[34]}$ 研究发现, 高生产力类型穗后氮素转运量和转运率 显著高于中等生产力类型和低生产力类型, 且随着 生产力的提高, 氮素吸收利用率、氮素生理利用率、 氮素农学利用率和氮肥偏生产力均显著增加。本研 究中, 3 种类型花后叶片氮素转运量相当, 高产氮高 效型品种花后茎鞘向穗部氮素转运量显著高于高产 氮中效型和中产氮中效型。高产氮高效型品种花后 氮素从茎鞘、叶片向穗部的高效运转促进了籽粒生 长发育, 增强了穗部氮素吸收能力, 提高了穗部氮 素积累量, 保证了高产的形成, 从而获得了较高的 氮素回收利用率、农学利用率、生理利用率、偏生 
产力和收获指数。综上, 提高籼粳杂交稻花后茎鞘 氮素转运量有助于提高成熟期穗部氮素积累量、产 量和氮素利用效率。

氮素生理利用率是指作物对所吸收的肥料氮素 在作物体内的利用率, 即施用氮肥而增加的产量与 相应氮素积累量的增加量之比。本研究中, 中产氮 中效型百千克籽粒吸氮量显著高于高产氮高效型和 高产氮中效型, 氮素回收利用率显著高于高产氮中 效型, 氮素生理利用率却显著低于其他两种类型。 这说明, 中产氮中效型吸氮量较高, 但对氮素的利 用水平较低, 这可能有两方面的原因。(1) 中产氮中 效型品种对氮素缺失比较敏感, 不施肥条件下吸氮 量较低, 施肥后吸氮量显著提高, 因此氮素回收 利用率较高; (2) 可能与成熟期茎鞘氮素积累量有 关 ${ }^{[26,36]}$, 中产氮中效型品种株高较高, 为了防止后 期发生倒伏, 茎鞘需要维持一定的氮浓度 ${ }^{[34]}$, 保持 茎秆稳定性, 阻碍了花后氮素从茎鞘向穗部转运, 影响了生育后期碳氮代谢, 不利于产量的提高, 导 致氮素农学利用率、生理利用率和氮肥偏生产力等 指标较低。

\section{4 结论}

与高产氮中效型和中产氮中效型相比, 高产氮 高效型群体颖花量大; 生育前期分菜发生稳定, 无 效分覧少, 干物质和氮素积累量较低; 中期叶面积 指数、群体生长率和净同化率显著提高, 群体结构 优，干物质生产和氮素吸收能力强; 后期光合生产 能力强且持久, 花后茎鞘、叶片氮素转运量高, 氮素 吸收速率大, 穗部氮素积累多; 氮素回收利用率、农 学利用率、生理利用率、氮肥偏生产力和氮素收获 指数高。

\section{References}

[1] Peng S B, Tang Q Y, Zou Y B. Current status and challenges of rice production in China. Plant Prod Sci, 2009, 12: 3-8.

[2] Ray D K, Mueller N D, West P C, Foley J A. Yield trends are insufficient to double global crop production by 2050. PLoS One, 2013, 8: e66428.

[3] 宋昕蔚, 林建荣, 吴明国. 水稻籼粳亚种间杂种优势利用研究 进展与展望. 科学通报, 2016, 61: 3778-3786.

Song X W, Lin J R, Wu M G. Review and prospect on utilization of heterosis between indica-japonica rice subspecies. Chin Sci Bull, 2016, 61: 3778-3786 (in Chinese with English abstract).

[4] 金芝辉, 王起, 潘康蓉, 杨泟. 籼粳杂交水稻新组合角优 7850 机插高产栽培技术. 杂交水稻, 2019, 34(2): 40-42.

Jin Z H, Wang Q, Pan K R, Yang Y. High-yielding machine-transplanting cultivation techniques of new indica-japonica hybrid rice combination Yongyou 7850. Hybrid Rice, 2019, 34(2): 40-42 (in Chinese with English abstract).

[5] 吴明国, 林建荣, 宋昕蔚, 阮关海. 籼粳亚种间杂交水稻新组 合春优 84 的选育. 杂交水稻, 2014, 29(2): 19-21.

Wu M G, Lin J R, Song X W, Yuan G H. Breeding of new indica-japonica hybrid rice combination Chunyou 84. Hybrid Rice, 2014, 29(2): 19-21 (in Chinese with English abstract).

[6] 王林友, 王建军, 张礼霞, 祁永斌, 范宏环, 宋建, 金庆生. 籼 粳杂交稻新组合浙优 19 的选育与应用. 杂交水稻, 2018, 33(6): 27-30.

Wang L Y, Wang J J, Zhang L X, Qi Y B, Fan H H, Song J, Jin Q $\mathrm{S}$. Breeding and application of new indica-japonica hybrid rice combination Zheyou 19. Hybrid Rice, 2018, 33(6): 27-30 (in Chinese with English abstract).

[7] 王晓燕, 韦还和, 张洪程, 孙健, 张建民, 李超, 陆惠斌, 杨筠 文, 马荣荣, 许久夫, 王玨, 许跃进, 孙玉海. 水稻角优 12 产 量 $13.5 \mathrm{t} \mathrm{hm}^{-2}$ 以上超高产群体的生育特征. 作物学报, 2014, 40: 2149-2159.

Wang X Y, Wei H H, Zhang H C, Sun J, Zhang J M, Li C, Lu H B, Yang J W, Ma R R, Xu J F, Wang J, Xu Y J, Sun Y H. Population characteristics for super-high yielding hybrid rice Yongyou 12 ( >13.5 t ha ${ }^{-1}$ ). Acta Agron Sin, 2014, 40: 2149-2159 (in Chinese with English abstract).

[8] 花劲, 周年兵, 张军, 张洪程, 霍中洋, 周培建, 程飞虎, 李国 业, 黄大山, 陈忠平, 陈国梁, 戴其根, 许轫, 魏海燕, 高辉, 郭保卫. 双季晚稻甬优系列籼粳杂交稻超高产结构与群体形 成特征.中国农业科学, 2015, 48: 1023-1034.

Hua J, Zhou N B, Zhang J, Zhang H C, Huo Z Y, Zhou P J, Cheng F H, Li G Y, Huang D S, Chen Z P, Chen G L, Dai Q G, Xu K, Wei H Y, Gao H, Guo B W. The structure and formation characteristics of super-high yield population with late Yongyou series of indica-japonica hybrid rice in double-cropping rice area. Sci Agric Sin, 2015, 48: 1023-1034 (in Chinese with English abstract).

[9] 胡雅杰, 朱大伟, 钱海军, 曹伟伟, 邢志鹏, 张洪程, 周有炎, 陈厚存, 汪洪洋, 戴其根, 霍中洋, 许轲, 魏海燕, 郭保卫. 籼 粳杂交稻角优 2640 钵苗机插超高产群体若干特征探讨. 作物 学报, 2014, 40: 2016-2027.

Hu Y J, Zhu D W, Qian H J, Cao W W, Xing Z P, Zhang H C, Zhou Y Y, Chen H C, Wang H Y, Dai Q G, Huo Z Y, Xu K, Wei H Y, Guo B W. Some characteristics of mechanically transplanted pot seedlings in super-high yielding population of indicajaponica hybrid rice Yongyou 2640. Acta Agron Sin, 2014, 40: 2016-2027 (in Chinese with English abstract).

[10] 姜元华, 张洪程, 赵可, 许俊伟, 韦还和, 龙厚元, 王文婷, 戴 其根, 霍中洋, 许轫, 魏海燕, 郭保卫. 长江下游地区不同类 型水稻品种产量及其构成因素特征的研究. 中国水稻科学, 2014, 28: 621-631.

Jiang Y H, Zhang H C, Zhao K, Xu J W, Wei H H, Long H Y, Wang W T, Dai Q G, Huo Z Y, Xu K, Wei H Y, Guo B W. Difference in yield and its components characteristics of different type rice cultivars in the lower reaches of the Yangtze River. Chin J Rice Sci, 2014, 28: 621-631 (in Chinese with English abstract).

[11] 姜元华, 许俊伟, 赵可, 韦还和, 孙建军, 张洪程, 戴其根, 霍 中洋, 许轲, 魏海燕, 郭保卫. 角优系列籼粳杂交稻根系形态 与生理特征. 作物学报, 2015, 41: 89-99.

Jiang Y H, Xu J W, Zhao K, Wei H H, Sun J J, Zhang H C, Dai Q 
G, Huo Z Y, Xu K, Wei H Y, Guo B W. Root system morphological and physiological characteristics of indica-japonica hybrid rice of Yongyou series. Acta Agron Sin, 2015, 41: 89-99 (in Chinese with English abstract).

[12] 马荣荣, 许德海, 王晓燕, 禹盛苗, 金千瑜, 欧阳由男, 朱练 峰. 籼粳亚种间杂交稻角优 6 号超高产株形特征与竞争优势 分析. 中国水稻科学, 2007, 21: 281-286.

Ma R R, Xu D H, Wang X Y, Yu S M, Jin Q Y, Ou-Yang Y N, Zhu L F. Heterosis on plant morphology of Yongyou 6, an indicajaponica inter-subspecific super high-yielding hybrid rice. Chin $J$ Rice Sci, 2007, 21: 281-286 (in Chinese with English abstract).

[13] 姜元华, 许轫, 赵可, 孙建军, 韦还和, 许俊伟, 魏海燕, 郭保 卫, 霍中洋, 戴其根, 张洪程. 角优系列籼粳杂交稻的冠层结 构与光合特性. 作物学报, 2015, 41: 286-296.

Jiang Y H, Xu K, Zhao K, Sun J J, Wei H H, Xu J W, Wei H Y, Guo B W, Huo Z Y, Dai Q G, Zhang H C. Canopy structure and photosynthetic characteristics of Yongyou series of indicajaponica hybrid rice under high-yielding cultivation condition. Acta Agron Sin, 2015, 41: 286-296 (in Chinese with English abstract).

[14] 郭保卫, 花劲, 周年兵, 张洪程, 陈波, 舒鹏, 霍中洋, 周培建, 程飞虎, 黄大山, 陈忠平, 陈国梁, 陈恒, 戴其根, 许轫, 魏海 燕, 高辉. 双季晚稻不同类型品种产量及其群体动态特征差 异研究.作物学报, 2015, 41: 1220-1236.

Guo B W, Hua J, Zhou N B, Zhang H C, Chen B, Shu P, Huo Z Y, Zhou P J, Cheng F H, Huang D S, Chen Z P, Chen G L, Chen H, Dai Q G, Xu K, Wei H Y, Gao H. Difference in yield and population characteristics of different types of late rice cultivars in double-cropping rice area. Acta Agron Sin, 2015, 41: 1220-1236 (in Chinese with English abstract).

[15] 孟天瑶, 李晓芸, 李超, 韦还和, 史天宇, 马荣荣, 王晓燕, 杨 筠文, 戴其根, 张洪程. 角优系列籼粳杂交稻中熟高产品系的 株型特征. 中国水稻科学, 2016, 30: 170-180.

Meng T Y, Li X Y, Li C, Wei H H, Shi T Y, Ma R R, Wang X Y, Yang J W, Dai Q G, Zhang H C. Plant-type characteristics of high-yielding lines of Yongyou indica-japonica hybrid rice with medium maturity. Chin J Rice Sci, 2016, 30: 170-180 (in Chinese with English abstract).

[16] 姜元华, 张洪程, 赵可, 许俊伟, 韦还和, 王文婷, 孟天瑶, 戴 其根, 霍中洋, 许轲, 魏海燕, 郭保卫. 机插条件下籼粳杂交 稻茎秆的抗倒性评价及成因分析. 农业工程学报, 2014, 30(19): $19-29$.

Jiang Y H, Zhang H C, Zhao K, Xu J W, Wei H H, Wang W T, Meng T Y, Dai Q G, Huo Z Y, Xu K, Wei H Y, Guo B W. Evaluation and cause analysis of rice-stem lodging resistance for mechanical transplanted indica-japonica hybrid rice. Trans CSAE, 2014, 30(19): 19-29 (in Chinese with English abstract).

[17] Wang F, Peng S B. Yield potential and nitrogen use efficiency of China's super rice. J Integr Agric, 2017, 16: 1000-1008.

[18] Xu M G, Li D C, Li J M, Qin D Z, Hosen Y, Shen H P, Cong R H, $\mathrm{He} \mathrm{X}$ H. Polyolefin-coated urea decreases ammonia volatilization in a double rice system of southern China. Agron J, 2013, 105: $277-284$.

[19] Hou W F, Xue X X, Li X K, Muhammad R K, Yan J Y, Ren T, Cong R H, Lu J W. Interactive effects of nitrogen and potassium on: grain yield, nitrogen uptake and nitrogen use efficiency of rice in low potassium fertility soil in China. Field Crops Res, 2019, 236: 14-23.

[20] 李敏, 张洪程, 杨雄, 葛梦婕, 魏海燕, 戴其根, 霍中洋, 许轫. 高产氮高效型粳稻品种的叶片光合及衰老特性研究. 中国水 稻科学, 2013, 27: 168-176.

Li M, Zhang H C, Yang X, Ge M J, Wei H Y, Dai Q G, Huo Z Y, $\mathrm{Xu} \mathrm{K}$. Leaf photosynthesis and senescence characteristics of $\mathrm{ja}$ ponica rice cultivars with high yield and high $\mathrm{N}$-efficiency. Chin J Rice Sci, 2013, 27: 168-176 (in Chinese with English abstract).

[21] 李超, 韦还和, 许俊伟, 王子杰, 许轫, 张洪程, 戴其根, 霍中 洋, 魏海燕, 郭保卫. 角优系列籼粳杂交稻氮素积累与转运特 征. 植物营养与肥料学报, 2016, 22: 1177-1186.

Li C, Wei H H, Xu J W, Wang Z J, Xu K, Zhang H C, Dai Q G, Huo Z Y, Wei H Y, Guo B W. Characteristics of nitrogen uptake, utilization and translocation in the indica-japonica hybrid rice of Yongyou series. Plant Nutr Fert Sci, 2016, 22: 1177-1186 (in Chinese with English abstract).

[22] 陈贵, 陈梅, 张红梅, 王士否, 施卫明, 程旺大. 籼粳杂交稻 与常规粳稻产量、干物质氮素累积转运及氮素利用差异研究. 浙江农业学报, 2018, 30: 1992-2000.

Chen G, Chen M, Zhang H M, Wang S L, Shi W M, Cheng W D. Differences of yield, accumulation and translocation properties of dry matter and $\mathrm{N}$, and $\mathrm{N}$ use efficiency between indica-japonica hybrid rice and japonica rice. Acta Agric Zhejiangensis, 2018, 30: 1992-2000 (in Chinese with English abstract).

[23] 韦还和, 孟天瑶, 李超, 张洪程, 史天宇, 马荣荣, 王晓燕, 杨 筠文, 戴其根, 霍中洋, 许轲, 魏海燕, 郭保卫. 籼粳交超级 稻角优 538 的穗部特征及籽粒灌浆特性. 作物学报, 2015, 41: $1858-1869$.

Wei H H, Meng T Y, Li C, Zhang H C, Shi T Y, Ma R R, Wang X Y, Yang J W, Dai Q G, Huo Z Y, Xu K, Wei H Y, Guo B W. Panicle traits and grain-filling characteristics of indica-japonica hybrid super rice Yongyou 538. Acta Agron Sin, 2015, 41: 1858-1869 (in Chinese with English abstract).

[24] 郭保卫, 李超, 韦还和, 王子杰, 许轫, 张洪程, 戴其根, 霍中 洋, 魏海燕. 不同株高类型甬优系列籼粳杂交稻产量差异及 其形成机理. 核农学报, 2017, 31: 135-144.

Guo B W, Li C, Wei H H, Wang Z J, Xu K, Zhang H C, Dai Q G, Huo Z Y, Wei H Y. Yield difference and its formation mechanism of indica-japonica hybrid rice of Yongyou series in different types of plant height. J Nucl Agric Sci, 2017, 31: 135-144 (in Chinese with English abstract).

[25] 徐栋, 朱盈, 周否, 韩超, 郑雷鸣, 张洪程, 魏海燕, 王珏, 廖 桉桦, 蔡仕博. 不同类型籼粳杂交稻产量和品质性状差异及 其与灌浆结实期气候因素间的相关性. 作物学报, 2018, 44: $1548-1559$.

Xu D, Zhu Y, Zhou L, Han C, Zheng L M, Zhang H C, Wei H Y, Wang J, Liao A H, Cai S B. Differences in yield and grain quality among various types of indica-japonica hybrid rice and correlation between quality and climatic factors during grain filling period. Acta Agron Sin, 2018, 44: 1548-1559 (in Chinese with English abstract).

[26] 汪峰, 谌江华, 孙梅梅, 柴伟纲, 姚红燕, 戴瑶璐, 张玉屏, 朱 德峰, 陈若霞. 角优系列籼粳杂交稻株高变化对氮素利用率 的影响. 浙江农业学报, 2019, 31: 1-10. 
Wang F, Shen J H, Sun M M, Chai W G, Yao H Y, Dai Y L, Zhang Y P, Zhu D F, Chen R X. Effect of change of plant height on nitrogen use efficiency in Yongyou indica-japonica hybrid rice. Acta Agric Zhejiangensis, 2019, 31: 1-10 (in Chinese with English abstract).

[27] 韦还和, 孟天瑶, 李超, 张洪程, 戴其根, 马荣荣, 王晓燕, 杨

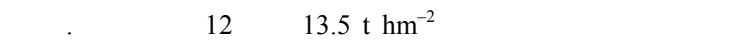
累、分配与利用特征. 作物学报, 2016, 42: 1363-1373.

Wei H H, Meng T Y, Li C, Zhang H C, Dai Q G, Ma R R, Wang $X$ Y, Yang J W. Accumulation, translocation and utilization characteristics of nitrogen in Yongyou 12 yielding over $13.5 \mathrm{t} \mathrm{ha}^{-1}$. Acta Agron Sin, 2016, 42: 1363-1373 (in Chinese with English abstract).

[28] 吴桂成, 张洪程, 钱银飞, 李德剑, 周有炎, 徐军, 吴文革, 戴 其根, 霍中洋, 许轫, 高辉, 徐宗进, 钱宗华, 孙菊英, 赵品恒. 粳型超级稻产量构成因素协同规律及超高产特征的研究. 中 国农业科学, 2010, 43: 266-276.

Wu G C, Zhang H C, Qian Y F, Li D J, Zhou Y Y, Xu J, Wu W G, Dai Q G, Huo Z Y, Xu K, Gao H, Xu Z J, Qian Z H, Sun J Y, Zhao $\mathrm{P}$ H. Rule of grain yield components from high yield to super-high yield and the characters of super-high yielding japonica super rice. Sci Agric Sin, 2010, 43: 266-276 (in Chinese with English abstract).

[29] 凌启鸿. 作物群体质量. 上海: 上海科技出版社, 2000. pp $1-210$.

Ling Q H. Quality of Crop Population. Shanghai: Shanghai Scientific and Technical Publishers, 2000. pp 1-210 (in Chinese).

[30] Wei H Y, Zhang H C, Eduardo B, Li H L, Cheng J Q, Dai Q G, Huo Z Y, Xu K, Guo B W. Different characteristics of high yield formation between inbred japonica super rice and inter-sub-specific hybrid super rice. Field Crops Res, 2016, 198: 179-187.

[31] 吴越, 胡静, 陈琛, 张家星, 李万元, 唐东南, 仲军, 羊彬, 朱 正康, 姚友礼, 王余龙, 董桂春. 江苏省早熟晚粳高产水稻新 品种氮素吸收利用特征及成因分析. 中国水稻科学, 2017, 31: 619-630.
Wu Y, Hu J, Chen C, Zhang J X, Li W Y, Tang D N, Zhong J, Yang B, Zhu Z K, Yao Y L, Wang Y L, Dong G C. Nitrogen absorption and utilization characteristics of the newly approved early-maturity late japonica rice cultivars in Jiangsu province. Chin J Rice Sci, 2017, 31: 619-630 (in Chinese with English abstract).

[32] Zhang Y L, Fan J B, Wang D S, Shen Q R. Genotypic differences in grain yield and physiological nitrogen use efficiency among rice cultivars. Pedosphere, 2009, 19: 681-691.

[33] Huang L Y, Yang D S, Li X X, Peng S B, Wang F. Coordination of high grain yield and high nitrogen use efficiency through large sink size and high post-heading source capacity in rice. Field Crops Res, 2019, 233: 49-58.

[34] 李敏, 张洪程, 马群, 杨雄, 李国业, 魏海燕, 戴其根, 霍中洋, 许轫. 不同氮肥群体最高生产力类型粳稻品种的氮素吸收利 用特性. 中国水稻科学, 2012, 26: 197-204.

Li M, Zhang H C, Ma Q, Yang X, Li G Y, Wei H Y, Dai Q G, Huo Z Y, Xu K. Nitrogen absorption and utilization characteristics of japonica rice cultivars with different productivities at their optimum nitrogen level. Chin J Rice Sci, 2012, 26: 197-204 (in Chinese with English abstract).

[35] 殷春渊, 张庆, 魏海燕, 张洪成, 戴其根, 霍中洋, 许珂, 马群, 杭杰, 张胜飞. 不同产量类型水稻基因型氮素吸收、利用效率 的差异. 中国农业科学, 2010, 43: 39-50.

Yin C Y, Zhang Q, Wei H Y, Zhang H C, Dai Q G, Huo Z Y, Xu $\mathrm{K}$, Ma Q, Hang J, Zhang S F. Differences in nitrogen absorption and use efficiency in rice genotypes with different yield performance. Sci Agric Sin, 2010, 43: 39-50 (in Chinese with English abstract).

[36] 张亚丽, 㚞剑波, 段英华, 王东升, 叶利庭, 沈其荣. 不同 基因型水稻氮利用效率的差异及评价. 土壤学报, 2008, 45: 267-273.

Zhang Y L, Fan J B, Duan Y H, Wang D S, Ye L T, Shen Q R. Variation of nitrogen use efficiency of rice different in genotype and its evaluation. Acta Pedol Sin, 2008, 45: 267-273 (in Chinese with English abstract). 